\title{
Coffee Polyphenols Change the Expression of STAT5B and ATF-2 Modifying Cyclin D1 Levels in Cancer Cells
}

\author{
Carlota Oleaga, ${ }^{1}$ Carlos J. Ciudad, ${ }^{1}$ Véronique Noé, ${ }^{1}$ and Maria Izquierdo-Pulido ${ }^{2}$ \\ ${ }^{1}$ Department of Biochemistry and Molecular Biology, School of Pharmacy, University of Barcelona, 08028 Barcelona, Spain \\ ${ }^{2}$ Department of Nutrition and Food Science, School of Pharmacy, University of Barcelona, 08028 Barcelona, Spain \\ Correspondence should be addressed to Véronique Noé, vnoe@ub.edu
}

Received 10 February 2012; Revised 16 May 2012; Accepted 18 May 2012

Academic Editor: Luciano Pirola

Copyright ( $) 2012$ Carlota Oleaga et al. This is an open access article distributed under the Creative Commons Attribution License, which permits unrestricted use, distribution, and reproduction in any medium, provided the original work is properly cited.

\begin{abstract}
Background. Epidemiological studies suggest that coffee consumption reduces the risk of cancer, but the molecular mechanisms of its chemopreventive effects remain unknown. Objective. To identify differentially expressed genes upon incubation of HT29 colon cancer cells with instant caffeinated coffee (ICC) or caffeic acid (CA) using whole-genome microarrays. Results. ICC incubation of HT29 cells caused the overexpression of 57 genes and the underexpression of 161, while CA incubation induced the overexpression of 12 genes and the underexpression of 32. Using Venn-Diagrams, we built a list of five overexpressed genes and twelve underexpressed genes in common between the two experimental conditions. This list was used to generate a biological association network in which STAT5B and ATF-2 appeared as highly interconnected nodes. STAT5B overexpression was confirmed at the mRNA and protein levels. For ATF-2, the changes in mRNA levels were confirmed for both ICC and CA, whereas the decrease in protein levels was only observed in CA-treated cells. The levels of cyclin D1, a target gene for both STAT5B and ATF-2, were downregulated by CA in colon cancer cells and by ICC and CA in breast cancer cells. Conclusions. Coffee polyphenols are able to affect cyclin D1 expression in cancer cells through the modulation of STAT5B and ATF-2.
\end{abstract}

\section{Introduction}

Polyphenols are the most abundant antioxidants in the diet. Their main dietary sources are fruits and plant-derived beverages such as fruit juices, tea, coffee, and red wine. Current evidence strongly supports a contribution of polyphenols to the prevention of cardiovascular diseases, cancers, and osteoporosis suggesting a role of these antioxidants in the prevention of neurodegenerative diseases and diabetes mellitus [1].

It is well established that polyphenol ingestion results in an increase of the plasma-antioxidant capacity. However, there is still some uncertainties about their efficiency to enhance the protection of cellular components, such as lipids or DNA, against oxidative stress in humans [2]. Polyphenols and other antioxidants were thought to protect cell constituents against oxidative damage by scavenging free radicals. However, this concept now appears to be an oversimplified view of their mode of action [3]. More likely, cells respond to polyphenols mainly through direct interactions with receptors or enzymes involved in signal transduction, which may result in modification of the redox status of the cell and may trigger a series of redox-dependent reactions [4]. This could also apply to the anticarcinogenic effects of polyphenols, which properties may be explained by many different mechanisms.

Hydroxycinnamic acids are a major class of polyphenols found in almost every plant [2]. The major representative of hydroxycinnamic acids is caffeic acid, which occurs in food mainly as an ester with quinic acid named chlorogenic acid (5-caffeoylquinic acid). Coffee is a major source of chlorogenic acid in the human diet; the daily intake in coffee drinkers is $0.5-1 \mathrm{~g}$ whereas coffee abstainers will usually ingest $<100 \mathrm{mg} /$ day. Studies have shown that approximately the $33 \%$ of ingested chlorogenic acid and the $95 \%$ of caffeic acid are absorbed intestinally [5]. Thus, about two-thirds of ingested chlorogenic acid reach the colon where it is probably metabolized to caffeic acid [6].

Bioavailability data suggest that the biological effects of chlorogenic acid would become apparent after its metabolism to caffeic acid, and hence the need of studying the effects of this acid. Chlorogenic acid and caffeic acid are 
antioxidants in vitro [7], and they might inhibit the formation of mutagenic and carcinogenic N-nitroso compounds since they are inhibitors of the $\mathrm{N}$-nitrosation reaction in vivo [8]. Furthermore, chlorogenic acid can inhibit DNA damage in vitro [9] as it inhibits lipid peroxidation-induced DNA adduct formation [10] and suppresses reactive oxygen species-mediated nuclear factor (NF- $\kappa \mathrm{B})$, activator protein1 (AP-1), and mitogen-activated protein kinase activation by upregulating antioxidant enzymes [11]. These studies suggested that coffee polyphenols are potent chemopreventive agents.

Recent meta-analyses demonstrate inverse associations between coffee intake and the risk of colon, liver, breast, and endometrial cancer [12-15]. Moreover, in prospective population-based cohort studies, the inverse association between coffee consumption and risk of cancer has been shown. The group of Naganuma [16] found that the consumption of at least one cup of coffee per day was associated with a $49 \%$ lower risk of upper gastrointestinal cancer in a Japanese population, while Wilson and collaborators [17] found that men who regularly drink coffee appeared to have a lower risk of developing a lethal form of prostate cancer. The lower risk was evident when consuming either regular or decaffeinated coffee. It has been proposed that the inverse association between coffee intake and colon cancer could be explained, at least in part, by the presence of chlorogenic acid in coffee [18]. Ganmaa et al. [19] observed a general protective effect of caffeine intake on breast cancer risk for both ER subtypes, but the effect was only found to be significant for ER-positive breast cancers. In this study, the association between caffeine and breast cancer was stronger among postmenopausal women with estrogen-receptor and progesterone-receptor-positive breast cancer than those with estrogen-receptor and progesterone-receptor negative breast cancer [19]. In another study, coffee drinking specifically reduced the risk of developing ER-negative breast cancer but not ER-positive breast cancer [20].

Although there is enough evidence from epidemiological data supporting that coffee seems to reduce the risk of certain cancers, the molecular mechanisms underlying the chemopreventive effects of coffee remain unknown. For this reason, the aim of our study was to determine the effect at the molecular level of coffee polyphenols at low concentrations equivalent to one cup of coffee, using as a model a human colon cancer cell line HT29 in a nutrigenomic approach. Furthermore, the effect of coffee polyphenols was also evaluated in breast cancer cells.

\section{Materials and Methods}

2.1. Materials and Chemicals. Cells were incubated with Instant Caffeinated Coffee (ICC) (regular lyophilized instant coffee) and Caffeic acid (CA, Sigma). Compounds were dissolved either in DMSO (CA), or sterile water (ICC), and stored at $-20^{\circ} \mathrm{C}$.

2.2. Cell Culture. Colon adenocarcinoma HT29 and breast cancer MCF-7 cell lines were routinely grown in Ham's F12 medium supplemented with $7 \%$ fetal bovine serum
(FBS, both from Gibco) at $37^{\circ} \mathrm{C}$ in a $5 \% \mathrm{CO}_{2}$ humidified atmosphere in $10 \mathrm{~cm}$ dish, or in $33 \mathrm{~mm}$ plate.

Cells were incubated with ICC or CA at concentrations equivalent to one cup of coffee. The concentrations used in cell incubations, $7 \mu \mathrm{g} / \mathrm{mL}$ in $\mathrm{H}_{2} \mathrm{O} \mathrm{mQ}$ for ICC and $1.68 \mu \mathrm{g} / \mathrm{mL}$ in DMSO for CA, respectively, took into account the amount of these compounds in one cup of coffee and their distribution in a regular human body with $75 \%$ water content. These concentrations did not cause any cytotoxic effect in the cell incubations as determined by the MTT assay [21].

2.3. Microarrays. Gene expression was analyzed by hybridization to The GeneChip Human Genome U133A plus 2.0 microarrays from Affymetrix, containing 47,000 transcripts and variants. HT29 cells were incubated with ICC and CA for $24 \mathrm{~h}$. Total RNA was prepared from triplicate samples using Speedtools Total RNA Extraction Kit (Biotools) following the recommendations of the manufacturer. RNA quality was tested by 2100 Bioanalyzer Eukaryote Total RNA Nano Series II (Agilent Technologies). Labeling, hybridization, and detection were carried out following the manufacturer's specifications at the IDIBAPS Genomic Service (Hospital Clínic, Barcelona).

2.4. Microarray Data Analyses. Quantification was carried out with GeneSpring GX v.11.5.1 software (Agilent Technologies), which allows multifilter comparisons using data from different experiments to perform the normalization, generation of lists, and the functional classification of the differentially expressed genes. The input data was subjected to preprocess baseline transformation using the Robust Multiarray Average summarization algorithm using the median of control samples. After grouping the triplicate of each experimental condition, list of differentially expressed genes could be generated by using volcano plot analysis. The expression of each gene is reported as the ratio of the value obtained after each condition relative to control condition after normalization and statistical analysis of the data. The corrected $P$ value cutoff applied was of $<0.05$; then the output of this statistical analysis was filtered by fold expression, selecting specifically those genes that had a differential expression of at least 1.3 -fold. Gene classification was established by the Gene Ontology database.

2.5. Common Genes between ICC and CA Treatments. Common genes were selected from the lists of differentially expressed genes for each treatment using Venn-Diagrams. The newly generated list contained both over and underexpressed genes.

2.6. Generation of Biological Association Networks. BANs were constructed with the aid of the Pathway Analysis within the GeneSpring v.11.5.1 (Agilent) as described in Selga et al. [22] with the list of common genes differentially expressed in both treatments. A filtered screening was processed by the program between our data and bibliographic interaction 
databases up to a total of 100 related genes. Network associations were confirmed in the literature.

2.7. RT Real-Time PCR. Total RNA was extracted from HT29 cells using Ultraspec (Biotex) in accordance with the manufacturer's instructions.

Complementary DNA was synthesized as described in Selga et al. [23] and the cDNA product was used for amplification by real time PCR. STAT5B and ATF-2 mRNA levels were determined in an ABI Prism 7000 Sequence Detection System (Applied Biosystems) using $3 \mu \mathrm{L}$ of the cDNA reaction and the assays-on-demand Hs00560035_m1 for STAT5B, Hs00153179_ml for ATF-2, and Hs00356991_m1 for APRT (all from Applied Biosystems). APRT mRNA was used as an endogenous control. The reaction was performed following the manufacturers recommendations. Fold changes in gene expression were calculated using the standard $\Delta \Delta \mathrm{Ct}$ method.

2.8. Western Blot. Whole extracts were obtained from $2.5 \times$ $10^{6}$ control or treated cells according to Selga et al. [23]. Five $\mu \mathrm{L}$ of the extract was used to determine protein concentration by the Bradford assay (Bio-Rad). The extracts were frozen in liquid $\mathrm{N}_{2}$ and stored at $-80^{\circ} \mathrm{C}$. Total extracts $(50 \mu \mathrm{g})$ were resolved on SDS-polyacrylamide gels and transferred to PVDF membranes (Immobilon P, Millipore) using a semidry electroblotter.

The SNAP i.d. protein detection system technology (Millipore) was used to probe the membranes. This system applies vacuum through the membrane to actively drive reagents to protein locations, unlike the traditional technique of diffusion over the membrane as a reagent transport. Table 1 compiles the antibodies used in the different determinations.

Signals were detected by secondary horseradish peroxidase-conjugated antibody, either anti-rabbit $(1: 5000$ or $1: 10000$ dilution; Dako) or anti-mouse $(1: 2500$ dilution, Amersham NIF 824) and enhanced chemiluminescence using the ECL method, as recommended by the manufacturer (Amersham). Chemiluminescence was detected with ImageQuant LAS 4000 Mini technology (GE Healthcare).

2.9. Statistical Methods. For the RT-PCR and Western blot analyses, values are expressed as the mean \pm SE of three different experiments. Data were evaluated by unpaired Student's $t$ test, and analyses were performed using the PASW Statistics v. 18.0.0. software.

\section{Results}

3.1. Effect of ICC and CA Incubations in HT29 Gene Expression. The expression profile of over 47,000 transcripts and variants included in the microarray HG U133 plus 2.0 from Affymetrix was compared between HT29 control cells and cells incubated with either CA or ICC, at nontoxic concentrations for $24 \mathrm{~h}$. GeneSpring GX software v.11.5.1 was used to analyze the results. A list of differentially expressed genes by 1.3 -fold with a $P$ value cutoff of $<0.05$ was generated as described in Methods. When HT29 cells were incubated with ICC, 57 genes were overexpressed whereas 161 genes were underexpressed. Among the overexpressed genes, $24 \%$ belonged to the Transcription factors category and $19 \%$ to Cell cycle or to Biosynthetic processes. Within the underexpressed genes, the category corresponding to cell cycle was the most affected (53\% of the genes) followed by Transcription factors (19\%) and Biosynthetic processes (12\%). Upon incubation with CA, 12 genes were overexpressed whereas 32 genes were underexpressed. Among the overexpressed genes, 33\% belonged to the Transcription factors category, $25 \%$ to Cell cycle, and 16,7\% to Biosynthetic processes or immune response. Within the underexpressed genes, again the category corresponding to Cell cycle was the most affected (30\% of the genes) followed by Biosynthetic processes $(15 \%)$ and Transcription factors (12\%). The lists of differentially expressed genes are presented as Tables 2, 3, 4, and 5. The data presented in this work have been deposited in the Gene Expression Omnibus (GEO, http://www.ncbi.nlm.nih.gov/geo/) and are accessible through GEO series accession number [GSM867162].

3.2. Generation of Biological Association Networks. A Biological Association Network (BAN) was constructed using the Pathway Analysis within GeneSpring v.11.5.1 as described in Methods using as the starting list the common genes differentially expressed upon incubation with CA and ICC. This list included five overexpressed genes and twelve underexpressed genes (Table 6). In the generated network, signal transducer and activator of transcription 5B (STAT5B) and activating transcription factor 2 (ATF-2) appeared as highly interconnected nodes (Figure 1). These two main nodes were selected for further validations. STAT5B was overexpressed with respect to the control by $23.8 \%$ in cells treated with ICC and by $33.4 \%$ in cells treated with CA, whereas ATF2 was found underexpressed in HT29 incubated with ICC (32.5\% decrease compared to the control) and with CA (26\% decrease).

3.3. Validation of STAT5B and ATF-2 Changes at the $m R N A$ and Protein Levels. STAT5B overexpression in HT29 cells upon incubation with CA and ICC was confirmed at the mRNA (1.16- and 1.3-fold compared to the control, respectively) and protein levels (1.5- and 1.2-fold compared to the control, respectively) (Figures 2(a) and 2(c)). In the case of ATF-2, the changes in mRNA levels were confirmed for both CA and ICC (0.88- and 0.86-fold compared to the control, respectively), whereas the decrease in protein levels was only observed in CA-treated cells (0.62-fold compared to the control) (Figures 2(b) and 2(d)).

3.4. Expression of Cyclin D1 upon Incubation with ICC and $C A$. Cyclin D1 is overexpressed at the mRNA and protein level in over $50 \%$ of the breast cancers either in the presence or absence of gene amplification, and it is one of the most commonly overexpressed proteins in breast cancer [24, 25]. Cyclin D1 transcription is regulated by STAT5 [26-29] and ATF-2 [30-32]. 


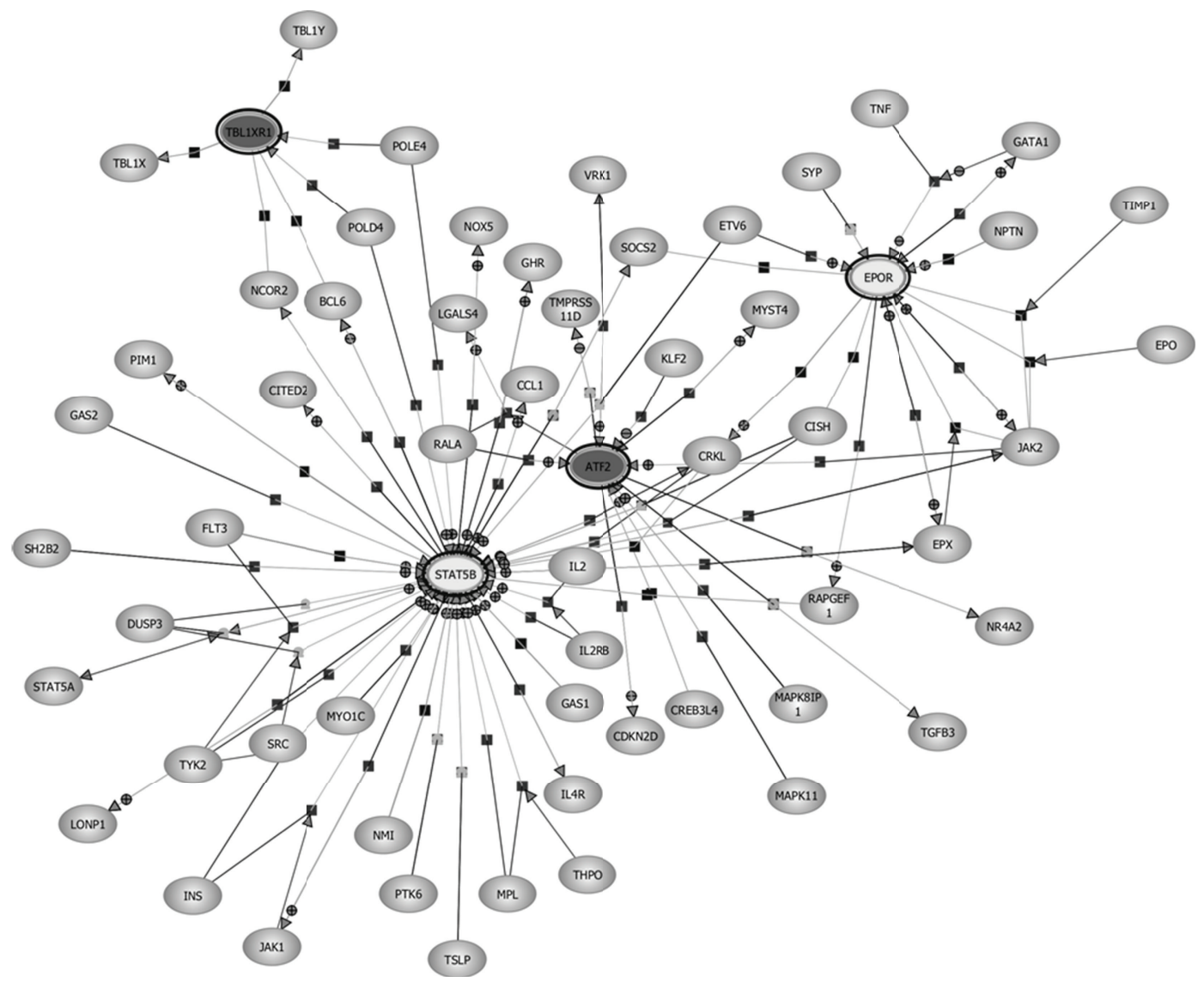

Figure 1: Biological association network (BAN) of differentially expressed genes in common between CA and ICC. The list of common genes between both treatments was used to construct a BAN with the Pathway Analysis software within GeneSpring v.11.5.1. An expanded network was constructed by setting an advanced filter that included the categories of binding, expression, metabolism, promoter binding, protein modification, and regulation. Only proteins are represented. The BAN shows the node genes STAT5B and ATF-2 that were further studied.

TABle 1

\begin{tabular}{lccc}
\hline Antibody & Molecular weight $(\mathrm{KDa})$ & Dilution used & Supplier \\
\hline STAT5B & 95 & $1: 200$ & sc-835, Santa Cruz Biotechnology Inc. \\
ATF-2 & 72 & $1: 200$ & sc-6233, Santa Cruz Biotechnology Inc. \\
Cyclin D1 & 38 & $1: 200$ & sc-8396, Santa Cruz Biotechnology Inc. \\
$\beta$-actin & 42 & $1: 200$ & A2066, Sigma \\
Tubulin & 60 & $1: 100$ & CP06, Calbiochem \\
\hline
\end{tabular}

We analyzed the levels of cyclin D1 by western blot in MCF-7 and HT29 cells upon incubation with ICC and CA. As shown in Figure 3(a), incubation of MCF-7 cells with either CA and ICC led to a drastic decrease in the levels of cyclin D1 protein, together with an increase in the levels of STAT5B, but not to a decrease in the levels of ATF-2. In HT29 cells, incubation with CA did not affect cyclin D1 levels, whereas the presence of ICC led to an increase in cyclin D1 levels 3 (b).

\section{Discussion}

In this work we analyzed the gene expression profile of human cancer cells treated with either ICC or CA. Caffeic acid was chosen since it is the main representative of hydroxycinnamic acids. Using microarrays we identified the differential expression of specific genes involved in several biological pathways. The changes in mRNA expression of two outlier genes, STAT5B and ATF-2, observed in the microarrays were confirmed by RT real-time PCR, and the changes in protein levels were also analyzed by Western blot. The selection of STAT5B and ATF-2 was made according to the results obtained in the construction of a biological association network. Finally, the modulation of cyclin D1, a target of STAT5B and ATF-2 transcription factors, upon incubation with coffee polyphenols was also established.

We show that ICC and the amount of CA of one cup of coffee are able to induce STAT5B mRNA and protein 


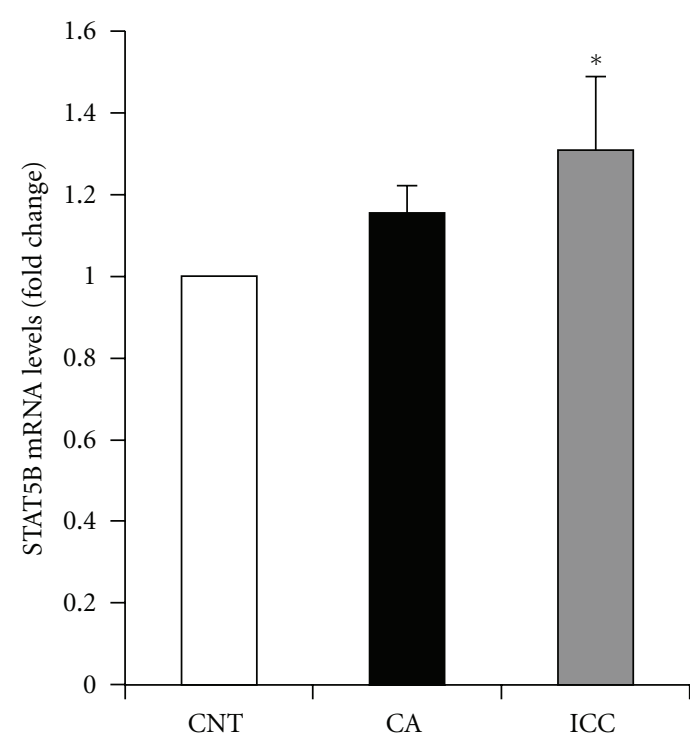

(a)

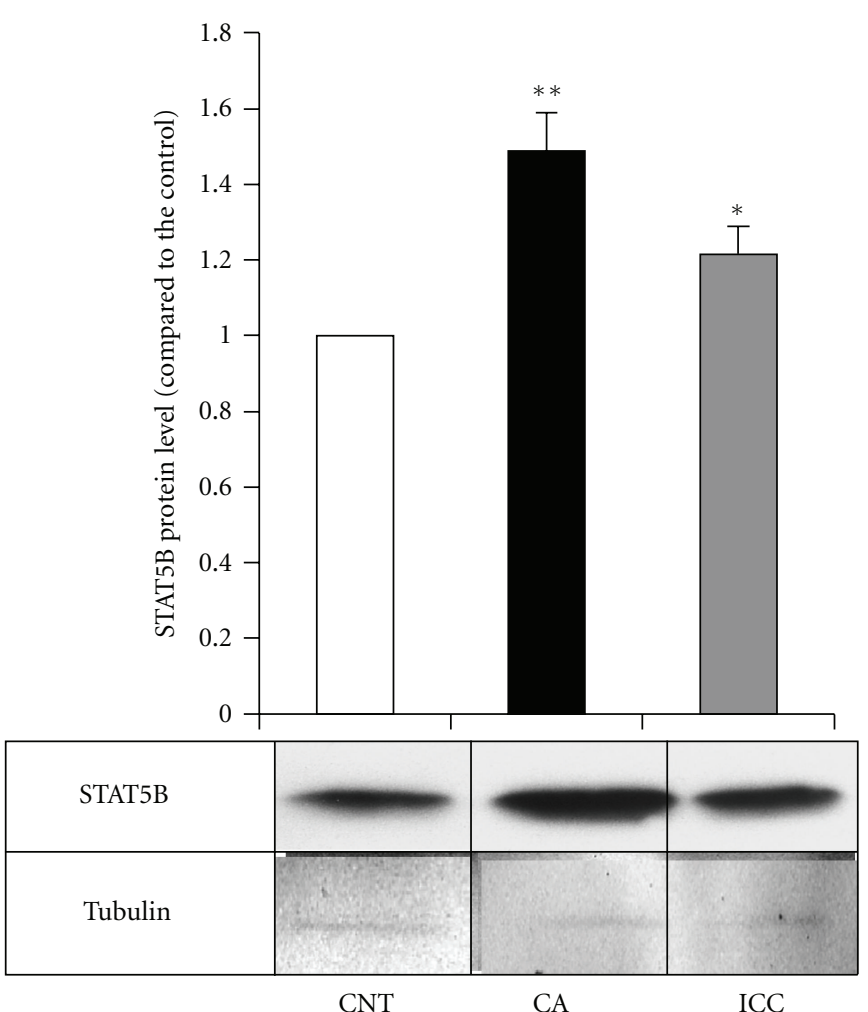

(c)

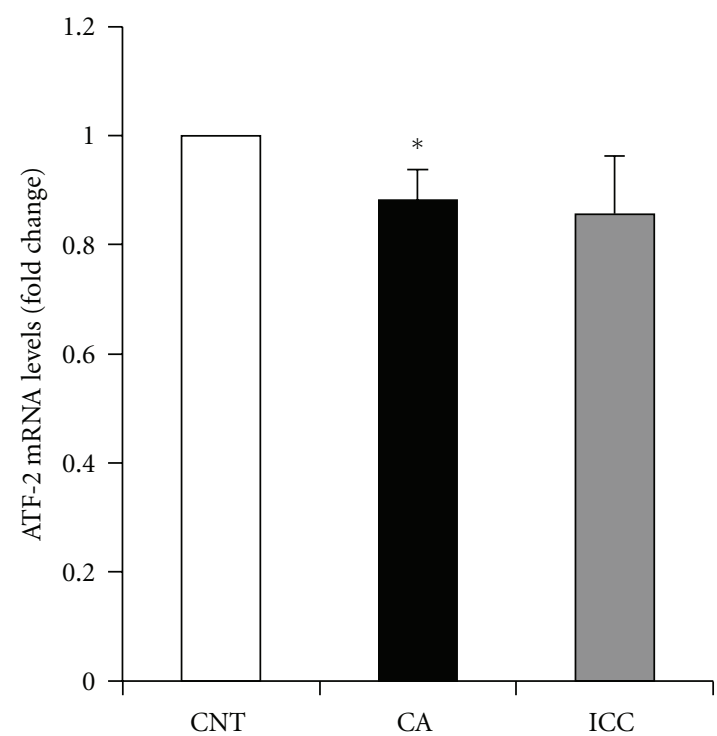

(b)

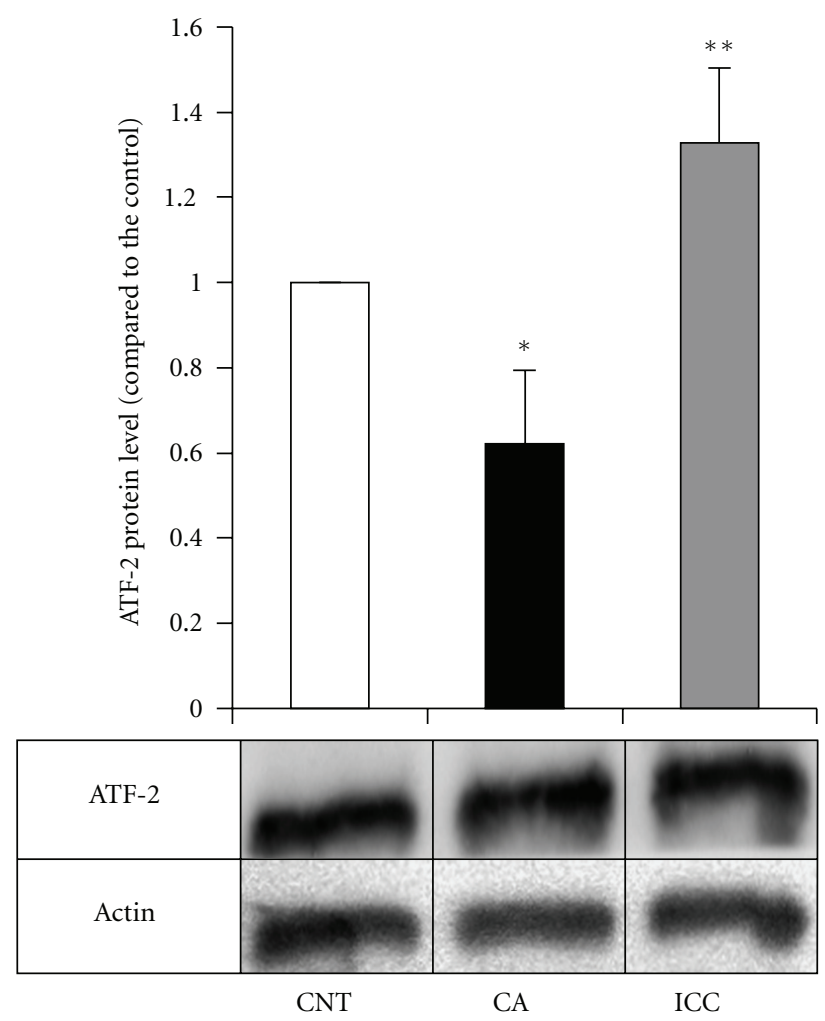

(d)

FIgure 2: Quantitation of mRNA and protein levels for STAT5B and ATF-2 in HT29 cells. The mRNA levels of STAT5B (a) and ATF-2 (b) were determined in control HT29 cells (empty bars) and cells treated with caffeic acid (CA, filled bars) and instant caffeinated coffee (ICC, grey bars) by RT real-time PCR as described in Methods. Results are expressed in fold changes compared to the control and are the mean \pm SE of 3 different experiments. ${ }^{*} P<0.05$ compared with the corresponding control. The protein levels of STAT5B (c) and ATF-2 (d) were determined in control HT29 cells (empty bars) and cells treated with caffeic acid (CA, filled bars) and instant caffeinated coffee (ICC, grey bars) by Western blot. Blots were reprobed with an antibody against $\beta$-actin or tubulin to normalize the results. Results represent the mean \pm SE of 3 different experiments. ${ }^{*} P<0.05$ and ${ }^{* *} P<0.01$ compared with the corresponding control. 
TABLE 2: List of overexpressed genes in HT29 cells upon incubation with instant caffeinated coffee.

\begin{tabular}{|c|c|c|c|c|}
\hline Gene symbol & Gene title & $P$ value & FC absolute & Regulation \\
\hline CALM3 & Calmodulin 3 (phosphorylase kinase, delta) & 0.016 & 1.3 & $\mathrm{Up}$ \\
\hline CDC42EP1 & CDC42 effector protein (Rho GTPase binding) 1 & 0.027 & 1.3 & Up \\
\hline FOXN3 & Forkhead box N3 & 0.022 & 1.3 & Up \\
\hline KIR2DL1 & Killer cell immunoglobulin-like receptor, two domains, long cytoplasmic tail, 1 & 0.023 & 1.3 & Up \\
\hline ORAI2 & ORAI calcium release-activated calcium modulator 2 & 0.011 & 1.3 & Up \\
\hline RAPGEF1 & Rap guanine nucleotide exchange factor (GEF) 1 & 0.022 & 1.3 & Up \\
\hline STH & Saitohin & 0.031 & 1.3 & Up \\
\hline SLC39A3 & Solute carrier family 39 (zinc transporter), member 3 & 0.028 & 1.3 & Up \\
\hline ZNF397OS & Zinc finger protein 397 opposite strand & 0.024 & 1.3 & Up \\
\hline $\mathrm{ZP} 4$ & Zona pellucida glycoprotein 4 & 0.046 & 1.3 & Up \\
\hline FGFRL1 & Fibroblast growth factor receptor-like 1 & 0.035 & 1.31 & Up \\
\hline ITGA9 & Integrin, alpha 9 & 0.002 & 1.31 & Up \\
\hline IRAK1 & Interleukin-1 receptor-associated kinase 1 & 0.038 & 1.31 & Up \\
\hline OBSL1 & Obscurin-like 1 & 0.008 & 1.31 & Up \\
\hline RPS17L4 & Ribosomal protein S17-like 4 & 0.026 & 1.31 & Up \\
\hline STAT5B & Signal transducer and activator of transcription $5 \mathrm{~B}$ & 0.007 & 1.31 & Up \\
\hline TRABD & TraB domain containing & 0.043 & 1.31 & Up \\
\hline MYO9B & Myosin IXB & 0.041 & 1.32 & Up \\
\hline NME7 & Nonmetastatic cells 7, protein expressed in (nucleoside-diphosphate kinase) & 0.037 & 1.32 & Up \\
\hline RPS6KA4 & Ribosomal protein S6 kinase, $90 \mathrm{kDa}$, polypeptide 4 & 0.014 & 1.32 & Up \\
\hline SIRPA & Signal-regulatory protein alpha & 0.019 & 1.32 & Up \\
\hline TBX20 & T-box 20 & 0.035 & 1.32 & Up \\
\hline TCF20 & Transcription factor $20(\mathrm{AR} 1)$ & 0.022 & 1.32 & Up \\
\hline ALDH3B1 & Aldehyde dehydrogenase 3 family, member B1 & 0.005 & 1.33 & Up \\
\hline BGN & Biglycan & 0.029 & 1.33 & Up \\
\hline GNB4 & Guanine nucleotide binding-protein ( $\mathrm{G}$ protein), b-polypeptide 4 & 0.044 & 1.33 & Up \\
\hline IFNA17 & Interferon, alpha 17 & 0.026 & 1.33 & Up \\
\hline KY & Kyphoscoliosis peptidase & 0.013 & 1.33 & Up \\
\hline SCARF1 & Scavenger receptor class F, member 1 & 0.025 & 1.33 & $\mathrm{Up}$ \\
\hline SERPINB8 & Serpin peptidase inhibitor, clade B (ovalbumin), member 8 & 0.01 & 1.33 & $\mathrm{Up}$ \\
\hline FST & Follistatin & 0.025 & 1.34 & Up \\
\hline MOGAT1 & Monoacylglycerol O-acyltransferase 1 & 0.009 & 1.34 & Up \\
\hline PPARGC1A & Peroxisome proliferator-activated receptor gamma, coactivator 1 alpha & 0.015 & 1.34 & Up \\
\hline SUCLG2 & Succinate-CoA ligase, GDP-forming, beta subunit & 0.011 & 1.34 & Up \\
\hline SULT1B1 & Sulfotransferase family, cytosolic, 1B, member 1 & 0.018 & 1.34 & Up \\
\hline TBX10 & T-box 10 & 0.011 & 1.34 & Up \\
\hline ZNF503 & Zinc finger protein 503 & 0.022 & 1.34 & Up \\
\hline HBA1 & Hemoglobin, alpha 1 & 0.04 & 1.35 & Up \\
\hline MEPE & Matrix, extracellular phosphoglycoprotein with ASARM motif & 0.001 & 1.35 & Up \\
\hline PPP1CB & Protein phosphatase 1 , catalytic subunit, beta isoform & 0.03 & 1.35 & Up \\
\hline ARV1 & ARV1 homolog (S. cerevisiae) & 0.011 & 1.36 & Up \\
\hline BCL3 & B-cell CLL/lymphoma 3 & 0.034 & 1.36 & Up \\
\hline CTRC & Chymotrypsin C (caldecrin) & 0.045 & 1.36 & Up \\
\hline EPOR & Erythropoietin receptor & 0.008 & 1.37 & Up \\
\hline HMGA1 & High-mobility group AT-hook 1 & 0.039 & 1.37 & Up \\
\hline IL19 & Interleukin 19 & 0.018 & 1.38 & $\mathrm{Up}$ \\
\hline $\mathrm{ABCC} 12$ & ATP-binding cassette, subfamily C (CFTR/MRP), member 12 & $6.00 \mathrm{E}-04$ & 1.39 & Up \\
\hline RAI1 & Retinoic acid induced 1 & 0.017 & 1.39 & Up \\
\hline
\end{tabular}


TABle 2: Continued.

\begin{tabular}{|c|c|c|c|c|}
\hline Gene symbol & Gene title & $P$ value & FC absolute & Regulation \\
\hline KLF5 & Kruppel-like factor 5 (intestinal) & 0.028 & 1.4 & Up \\
\hline CBWD1 & COBW domain containing 1 & 0.044 & 1.41 & Up \\
\hline ASAH3 & $\mathrm{N}$-acylsphingosine amidohydrolase (alkaline ceramidase) 3 & 0.039 & 1.43 & Up \\
\hline ABHD14B & Abhydrolase domain containing 14B & 0.03 & 1.45 & Up \\
\hline TLN1 & Talin 1 & 0.049 & 1.45 & Up \\
\hline ARHGAP23 & Rho GTPase-activating protein 23 & 0.024 & 1.65 & Up \\
\hline HINT3 & Histidine triad nucleotide binding protein 3 & 0.002 & 1.77 & Up \\
\hline ARHGDIA & Rho GDP dissociation inhibitor (GDI) alpha & 0.034 & 1.83 & Up \\
\hline CALR & Calreticulin & 0.007 & 1.93 & Up \\
\hline
\end{tabular}

The table shows the list of overexpressed genes by 1.3 -fold with a $P$ value $<0.05$ obtained in cells treated with instant caffeinated coffee and includes the gene symbol for all genes, and their associated description. The ratio columns correspond to the absolute fold change in expression relative to the control group and the type of regulation (up: upregulation).
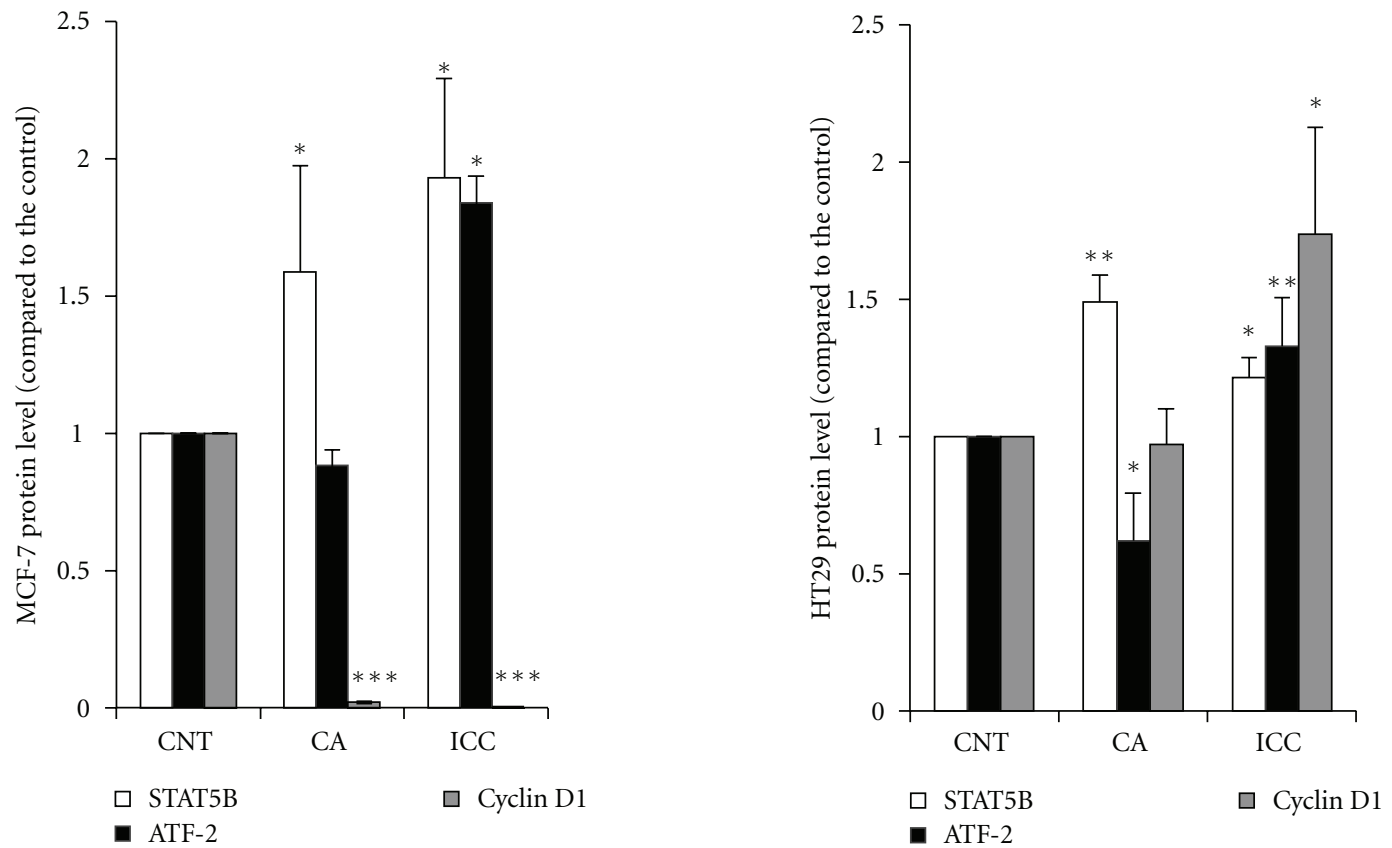

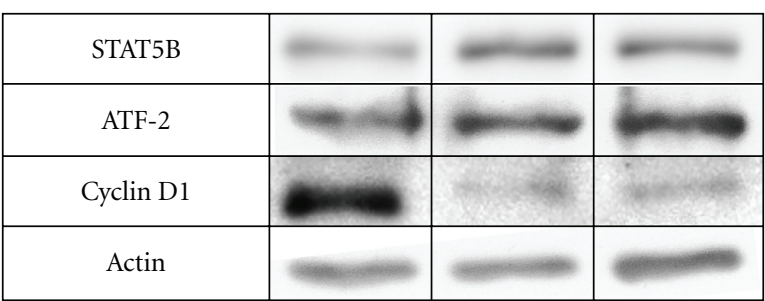

(a)

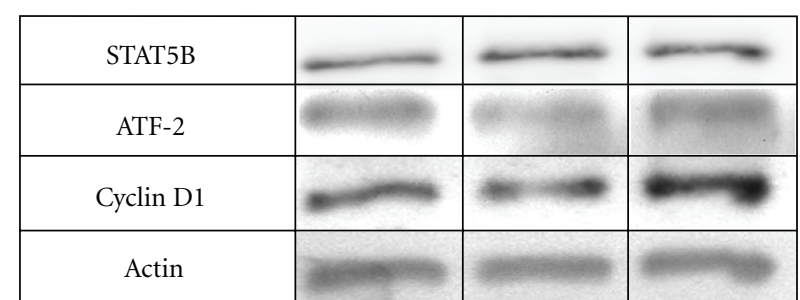

(b)

FIgURE 3: Expression of cyclin D1 upon incubation with ICC and CA in HT29 and MCF-7 cells. (a) Quantitation of STAT5b (empty bars), ATF-2 (filled bars), and cyclin D1 (grey bars) protein levels in MCF-7 cells. The protein levels were determined in control MCF-7 cells $(\mathrm{CNT})$ and cells treated with caffeic acid (CA) and instant coffee (ICC) by Western blot. Blots were reprobed with an antibody against $\beta$-actin to normalize the results. Results represent the mean \pm SE of 3 different experiments. ${ }^{*} P<0.05$ and ${ }^{* * *} P<0.001$ compared with the corresponding control. (b) Quantitation of STAT5b (empty bars), ATF-2 (filled bars), and cyclin D1 (grey bars) protein levels in HT29 cells. The protein levels were determined in control HT29 cells (CNT) and cells treated with caffeic acid (CA) and instant coffee (ICC) by Western blot. Blots were reprobed with an antibody against $\beta$-actin to normalize the results. Results represent the mean \pm SE of 3 different experiments. ${ }^{*} P<0.05$ and ${ }^{* *} P<0.01$ compared with the corresponding control. 
TABLE 3: List of underexpressed genes in HT29 cells upon incubation with instant coffee.

\begin{tabular}{|c|c|c|c|c|}
\hline Gene symbol & Gene title & $P$ value & FC absolute & Regulation \\
\hline ACBD5 & Acyl-coenzyme A binding domain containing 5 & 0.017 & 1.3 & Down \\
\hline CXADR & Coxsackie virus and adenovirus receptor & 0.015 & 1.3 & Down \\
\hline FANCD2 & Fanconi anemia, complementation group D2 & 0.047 & 1.3 & Down \\
\hline FRYL & FRY-like & 0.039 & 1.3 & Down \\
\hline NUB1 & Negative regulator of ubiquitin-like proteins 1 & 0.029 & 1.3 & Down \\
\hline PBRM1 & Polybromo 1 & 0.004 & 1.3 & Down \\
\hline PRKACB & Protein kinase, cAMP-dependent, catalytic, beta & 0.033 & 1.3 & Down \\
\hline RIF1 & RAP1 interacting factor homolog (yeast) & 0.012 & 1.3 & Down \\
\hline SLC39A6 & Solute carrier family 39 (zinc transporter), member 6 & 0.022 & 1.3 & Down \\
\hline TMEM170 & Transmembrane protein 170 & 0.032 & 1.3 & Down \\
\hline WDR26 & WD repeat domain 26 & 0.028 & 1.3 & Down \\
\hline RNGTT & RNA guanylyltransferase and $5^{\prime}$-phosphatase & 0.04 & 1.3 & Down \\
\hline CTDSPL2 & CTD small phosphatase like 2 & 0.03 & 1.3 & Down \\
\hline ZC3H11A & Zinc finger $\mathrm{CCCH}$-type containing 11A & 0.014 & 1.3 & Down \\
\hline TMOD3 & Tropomodulin 3 (ubiquitous) & 0.0171 & 1.3 & Down \\
\hline CPD & Carboxypeptidase D & 0.002 & 1.31 & Down \\
\hline $\mathrm{CBL}$ & Cas-Br-M ecotropic retroviral transforming sequence & 0.008 & 1.31 & Down \\
\hline CDC42SE2 & CDC42 small effector 2 & 0.022 & 1.31 & Down \\
\hline CLN5 & Ceroid-lipofuscinosis, neuronal 5 & 0.001 & 1.31 & Down \\
\hline DDX3X & DEAD (Asp-Glu-Ala-Asp) box polypeptide 3, X-linked & 0.027 & 1.31 & Down \\
\hline FGFR1OP2 & FGFR1 oncogene partner 2 & 0.049 & 1.31 & Down \\
\hline LRRFIP1 & Leucine-rich repeat (in FLII) interacting protein 1 & 0.026 & 1.31 & Down \\
\hline PDCD4 & Programmed cell death 4 & 0.005 & 1.31 & Down \\
\hline REPS2 & RALBP1-associated Eps domain containing 2 & 0.046 & 1.31 & Down \\
\hline SLC7A6 & Solute carrier family 7 , member 6 & 0.002 & 1.31 & Down \\
\hline TFRC & Transferrin receptor $(\mathrm{p} 90, \mathrm{CD} 71)$ & 0.038 & 1.31 & Down \\
\hline TMEM19 & Transmembrane protein 19 & 0.024 & 1.31 & Down \\
\hline AGPS & Alkylglycerone phosphate synthase & 0.001 & 1.31 & Down \\
\hline SLC4A7 & Solute carrier family 4 , member 7 & 0.028 & 1.31 & Down \\
\hline SPTAN1 & Spectrin, alpha, nonerythrocytic 1 (alpha-fodrin) & 0.02 & 1.31 & Down \\
\hline GPD2 & Glycerol-3-phosphate dehydrogenase 2 (mitochondrial) & 0.033 & 1.31 & Down \\
\hline BICD1 & Bicaudal D homolog 1 (Drosophila) & 0.008 & 1.31 & Down \\
\hline FBXW11 & F-box and WD repeat domain containing 11 & 0.025 & 1.31 & Down \\
\hline BCLAF1 & BCL2-associated transcription factor 1 & 0.025 & 1.32 & Down \\
\hline CDH1 & Cadherin 1, type 1, E-cadherin (epithelial) & 0.011 & 1.32 & Down \\
\hline CLK4 & CDC-like kinase 4 & 0.049 & 1.32 & Down \\
\hline PTAR1 & Protein prenyltransferase alpha subunit repeat containing 1 & 0.027 & 1.32 & Down \\
\hline SMEK2 & SMEK homolog 2, suppressor of mek1 (Dictyostelium) & 0.012 & 1.32 & Down \\
\hline CEPT1 & Choline/ethanolamine phosphotransferase 1 & 0.038 & 1.32 & Down \\
\hline SAR1A & SAR1 gene homolog A (S. cerevisiae) & 0.033 & 1.32 & Down \\
\hline PDGFC & Platelet-derived growth factor C & 0.02 & 1.32 & Down \\
\hline NFAT5 & Nuclear factor of activated T-cells 5 , tonicity responsive & 0.045 & 1.32 & Down \\
\hline FRS2 & Fibroblast growth factor receptor substrate 2 & 0.03 & 1.32 & Down \\
\hline BMS1P5 & BMS1 pseudogene 5 & 0.036 & 1.33 & Down \\
\hline GLS & Glutaminase & $5.00 \mathrm{E}-04$ & 1.33 & Down \\
\hline LMAN1 & Lectin, mannose binding, 1 & 7.00E-04 & 1.33 & Down \\
\hline ARHGAP18 & Rho GTPase-activating protein 18 & $8.00 \mathrm{E}-04$ & 1.33 & Down \\
\hline
\end{tabular}


Table 3: Continued.

\begin{tabular}{|c|c|c|c|c|}
\hline Gene symbol & Gene title & $P$ value & FC absolute & Regulation \\
\hline ARHGAP5 & Rho GTPase-activating protein 5 & 0.006 & 1.33 & Down \\
\hline CCNE2 & Cyclin E2 & 0.036 & 1.33 & Down \\
\hline SPCS3 & Signal peptidase complex subunit 3 homolog (S. cerevisiae) & 0.008 & 1.33 & Down \\
\hline NCOA2 & Nuclear receptor coactivator 2 & 0.005 & 1.33 & Down \\
\hline SRPRB & Signal recognition particle receptor, B subunit & 0.018 & 1.33 & Down \\
\hline TLK1 & Tousled-like kinase 1 & 0.04 & 1.33 & Down \\
\hline NCOA3 & Nuclear receptor coactivator 3 & 0.048 & 1.33 & Down \\
\hline STRN3 & Striatin, calmodulin-binding protein 3 & $2.00 \mathrm{E}-04$ & 1.33 & Down \\
\hline AP1G1 & Adaptor-related protein complex 1 , gamma 1 subunit & 0.004 & 1.34 & Down \\
\hline B3GALNT2 & Beta-1,3-N-acetylgalactosaminyltransferase 2 & 0.034 & 1.34 & Down \\
\hline PPHLN1 & Periphilin 1 & $2.00 \mathrm{E}-04$ & 1.34 & Down \\
\hline SNX13 & Sorting nexin 13 & 0.001 & 1.34 & Down \\
\hline TMED2 & Transmembrane emp24 domain-trafficking protein 2 & 0.041 & 1.34 & Down \\
\hline BRWD1 & Bromodomain and WD repeat domain containing 1 & 0.011 & 1.34 & Down \\
\hline HLA-B & Major histocompatibility complex, class I, B & 0.028 & 1.34 & Down \\
\hline CHP & Calcium-binding protein $\mathrm{P} 22$ & 0.002 & 1.34 & Down \\
\hline MTMR9 & Myotubularin-related protein 9 & 0.026 & 1.34 & Down \\
\hline DCUN1D4 & DCN1, defective in cullin neddylation 1, domain containing 4 & 0.031 & 1.34 & Down \\
\hline ARL6IP2 & ADP-ribosylation factor-like 6 interacting protein 2 & 0.02 & 1.35 & Down \\
\hline GLIS3 & GLIS family zinc finger 3 & 0.01 & 1.35 & Down \\
\hline LARP4 & La ribonucleoprotein domain family, member 4 & 0.019 & 1.35 & Down \\
\hline PTPLB & Protein tyrosine phosphatase-like member b & 0.036 & 1.35 & Down \\
\hline TRAM1 & Translocation-associated membrane protein 1 & 0.002 & 1.35 & Down \\
\hline TMEM64 & Transmembrane protein 64 & 0.001 & 1.35 & Down \\
\hline CBFB & Core-binding factor, beta subunit & 0.005 & 1.35 & Down \\
\hline SELT & Selenoprotein $\mathrm{T}$ & 0.002 & 1.35 & Down \\
\hline PEX13 & Peroxisome biogenesis factor 13 & 0.011 & 1.35 & Down \\
\hline TNKS2 & TRF1-interacting ankyrin-related ADP-ribose polymerase 2 & 0.034 & 1.35 & Down \\
\hline TMPO & Thymopoietin & 0.001 & 1.35 & Down \\
\hline LIN7C & Lin-7 homolog C (C. elegans) & 0.007 & 1.35 & Down \\
\hline MTA2 & Metastasis-associated 1 family, member 2 & 0.013 & 1.36 & Down \\
\hline TMEM168 & Transmembrane protein 168 & 0.035 & 1.36 & Down \\
\hline CREBZF & CREB/ATF bZIP transcription factor & 0.016 & 1.36 & Down \\
\hline OSTF1 & Osteoclast-stimulating factor 1 & 0.002 & 1.36 & Down \\
\hline WDR57 & WD repeat domain 57 (U5 snRNP specific) & 0.001 & 1.36 & Down \\
\hline GLT25D1 & Glycosyltransferase 25 domain containing 1 & 0.008 & 1.36 & Down \\
\hline NAPG & N-ethylmaleimide-sensitive factor attachment protein, gamma & 0.015 & 1.36 & Down \\
\hline CCDC126 & Coiled-coil domain containing 126 & 0.039 & 1.37 & Down \\
\hline LASS6 & LAG1 homolog, ceramide synthase 6 & 0.005 & 1.37 & Down \\
\hline MYSM1 & Myb-like, SWIRM and MPN domains 1 & 0.021 & 1.37 & Down \\
\hline CYP51A1 & Cytochrome P450, family 51, subfamily A, polypeptide 1 & 0.007 & 1.37 & Down \\
\hline PDE4DIP & Phosphodiesterase 4D interacting protein (myomegalin) & 0.024 & 1.37 & Down \\
\hline SAP30L & SAP30-like & 0.012 & 1.37 & Down \\
\hline PTPRJ & Protein tyrosine phosphatase, receptor type, J & 0.011 & 1.37 & Down \\
\hline PGGT1B & Protein geranylgeranyltransferase type I, beta subunit & $9.00 \mathrm{E}-04$ & 1.37 & Down \\
\hline ASPH & Aspartate beta-hydroxylase & 0.011 & 1.37 & Down \\
\hline SEMA3C & Sema domain, (semaphorin) $3 \mathrm{C}$ & 0.036 & 1.38 & Down \\
\hline WDR76 & WD repeat domain 76 & 0.016 & 1.38 & Down \\
\hline
\end{tabular}


Table 3: Continued.

\begin{tabular}{|c|c|c|c|c|}
\hline Gene symbol & Gene title & $P$ value & FC absolute & Regulation \\
\hline ATP13A3 & ATPase-type $13 \mathrm{~A} 3$ & 0.002 & 1.38 & Down \\
\hline LMBR1 & Limb region 1 homolog (mouse) & 0.014 & 1.38 & Down \\
\hline GLUD1 & Glutamate dehydrogenase 1 & 0.001 & 1.39 & Down \\
\hline GSTCD & Glutathione S-transferase, C-terminal domain containing & 0.029 & 1.39 & Down \\
\hline SPTLC1 & Serine palmitoyltransferase, subunit 1 & 0.02 & 1.39 & Down \\
\hline U2AF1 & U2 small nuclear RNA auxiliary factor 1 & $9.00 \mathrm{E}-04$ & 1.39 & Down \\
\hline UHMK1 & U2AF homology motif (UHM) kinase 1 & 0.007 & 1.39 & Down \\
\hline ARGLU1 & Arginine and glutamate-rich 1 & $6.00 \mathrm{E}-04$ & 1.39 & Down \\
\hline ANKRD12 & Ankyrin repeat domain 12 & 0.03 & 1.39 & Down \\
\hline PPP3R1 & Protein phosphatase 3 , regulatory subunit $\mathrm{B}$, alpha isoform & 0.023 & 1.39 & Down \\
\hline XRN1 & $5^{\prime}-3^{\prime}$ exoribonuclease 1 & 0.019 & 1.4 & Down \\
\hline CLSPN & Claspin homolog (Xenopus laevis) & 0.013 & 1.4 & Down \\
\hline CXADRP1 & Coxsackie virus and adenovirus receptor pseudogene 1 & 0.034 & 1.4 & Down \\
\hline G3BP1 & GTPase-activating protein- (SH3 domain) binding protein 1 & 0.002 & 1.4 & Down \\
\hline TMEM30A & Transmembrane protein $30 \mathrm{~A}$ & 0.01 & 1.4 & Down \\
\hline CLCN3 & Chloride channel 3 & 0.035 & 1.41 & Down \\
\hline STK4 & Serine/threonine kinase 4 & 0.039 & 1.41 & Down \\
\hline ZNF644 & Zinc finger protein 644 & 0.02 & 1.41 & Down \\
\hline TCP11L1 & T-complex 11 (mouse)-like 1 & 0.014 & 1.41 & Down \\
\hline SFRS6 & Splicing factor, arginine/serine-rich 6 & 0.031 & 1.41 & Down \\
\hline NPL & $\mathrm{N}$-acetylneuraminate pyruvate lyase & 0.006 & 1.41 & Down \\
\hline G3BP2 & GTPase-activating protein- (SH3 domain) binding protein 2 & 0.001 & 1.42 & Down \\
\hline HNRNPU & Heterogeneous nuclear ribonucleoprotein $\mathrm{U}$ & 0.01 & 1.42 & Down \\
\hline TBL1XR1 & Transducin (beta)-like 1 X-linked receptor 1 & 0.001 & 1.42 & Down \\
\hline PHTF2 & Putative homeodomain transcription factor 2 & 0.002 & 1.42 & Down \\
\hline ADAM10 & ADAM metallopeptidase domain 10 & 0.011 & 1.43 & Down \\
\hline ADAM9 & ADAM metallopeptidase domain 9 (meltrin gamma) & 0.01 & 1.43 & Down \\
\hline MALAT1 & Metastasis-associated lung adenocarcinoma transcript 1 & 0.04 & 1.43 & Down \\
\hline SCARB2 & Scavenger receptor class $\mathrm{B}$, member 2 & 0.001 & 1.43 & Down \\
\hline CANX & Calnexin & 0.043 & 1.43 & Down \\
\hline CASP2 & Caspase 2, apoptosis-related cysteine peptidase & 0.033 & 1.43 & Down \\
\hline TRPS1 & Trichorhinophalangeal syndrome I & 0.005 & 1.44 & Down \\
\hline ZFX & Zinc finger protein, $\mathrm{X}$-linked & 0.033 & 1.44 & Down \\
\hline SGPL1 & Sphingosine-1-phosphate lyase 1 & 0.04 & 1.44 & Down \\
\hline PTPN11 & Protein tyrosine phosphatase, nonreceptor type 11 & 0.045 & 1.44 & Down \\
\hline SFRS11 & Splicing factor, arginine/serine-rich 11 & 0.045 & 1.45 & Down \\
\hline B3GNT5 & Beta-1,3-N-acetylglucosaminyltransferase 5 & 0.021 & 1.45 & Down \\
\hline MAP3K1 & Mitogen-activated protein kinase kinase kinase 1 & 0.019 & 1.45 & Down \\
\hline SNHG4 & Small nucleolar RNA host gene (nonprotein coding) 4 & 0.004 & 1.46 & Down \\
\hline PARD6B & Par-6 partitioning defective 6 homolog beta (C. elegans) & 0.04 & 1.46 & Down \\
\hline ROD1 & ROD1 regulator of differentiation 1 (S. pombe) & 0.001 & 1.46 & Down \\
\hline SPTBN1 & Spectrin, beta, nonerythrocytic 1 & 0.02 & 1.48 & Down \\
\hline TXNDC1 & Thioredoxin domain containing 1 & 0.013 & 1.48 & Down \\
\hline ATF2 & Activating transcription factor 2 & 0.005 & 1.48 & Down \\
\hline RDX & Radixin & 0.043 & 1.48 & Down \\
\hline SCAMP1 & Secretory carrier membrane protein 1 & 0.009 & 1.48 & Down \\
\hline PTAR1 & Protein prenyltransferase alpha subunit repeat containing 1 & 0.018 & 1.49 & Down \\
\hline $\mathrm{RC} 3 \mathrm{H} 2$ & Ring finger and CCCH-type zinc finger domains 2 & 0.0037 & 1.49 & Down \\
\hline
\end{tabular}


TABle 3: Continued.

\begin{tabular}{|c|c|c|c|c|}
\hline Gene symbol & Gene title & $P$ value & FC absolute & Regulation \\
\hline ADAM17 & ADAM metallopeptidase domain 17 & 0.007 & 1.49 & Down \\
\hline FAM76B & Family with sequence similarity 76 , member B & 0.014 & 1.5 & Down \\
\hline ITGB8 & Integrin, beta 8 & $1.00 \mathrm{E}-04$ & 1.5 & Down \\
\hline TRIM23 & Tripartite motif-containing 23 & 0.005 & 1.5 & Down \\
\hline CASC5 & Cancer susceptibility candidate 5 & 0.019 & 1.52 & Down \\
\hline SLC16A1 & Solute carrier family 16 , member 1 & 0.002 & 1.52 & Down \\
\hline FNBP1 & Formin-binding protein 1 & 0.037 & 1.53 & Down \\
\hline PRKAR1A & Protein kinase, cAMP-dependent, regulatory, type I, alpha & $9.00 \mathrm{E}-04$ & 1.53 & Down \\
\hline B4GALT1 & Beta 1,4-galactosyltransferase, polypeptide 1 & 0.035 & 1.55 & Down \\
\hline MDM4 & Mdm4 p53-binding protein homolog (mouse) & 0.011 & 1.58 & Down \\
\hline FGD4 & FYVE, RhoGEF, and PH domain containing 4 & 0.001 & 1.59 & Down \\
\hline UBA6 & Ubiquitin-like modifier activating enzyme 6 & 8.00E-04 & 1.62 & Down \\
\hline ZDHHC21 & Zinc finger, DHHC-type containing 21 & 0.036 & 1.64 & Down \\
\hline REEP3 & Receptor accessory protein 3 & $7.00 \mathrm{E}-04$ & 1.65 & Down \\
\hline SSR3 & Signal sequence receptor, gamma & 0.014 & 1.65 & Down \\
\hline ZDHHC20 & Zinc finger, DHHC-type containing 20 & 0.003 & 1.66 & Down \\
\hline EIF2S3 & Eukaryotic translation initiation factor 2 , subunit 3 gamma & 0.001 & 1.7 & Down \\
\hline HNRNPH1 & Heterogeneous nuclear ribonucleoprotein $\mathrm{H} 1$ & 0.011 & 1.79 & Down \\
\hline ATL3 & Atlastin 3 & 0.001 & 2.02 & Down \\
\hline
\end{tabular}

The table shows the list of underexpressed genes by 1.3 -fold with a $P$ value $<0.05$ obtained in cells treated with instant caffeinated coffee and includes the gene symbol for all genes, and their associated description. The ratio columns correspond to the absolute fold change in expression relative to the control group and the type of regulation (down: downregulation).

TABLE 4: List of overexpressed genes in HT29 cells upon incubation with caffeic acid.

\begin{tabular}{|c|c|c|c|c|}
\hline Gene symbol & Gene title & $P$ value & FC absolute & Regulation \\
\hline SULT1B1 & Sulfotransferase family, cytosolic, 1B, member 1 & 0.02 & 1.3 & Up \\
\hline BCL6B & B-cell CLL/lymphoma 6, member B (zinc finger protein) & $3.00 \mathrm{E}-04$ & 1.3 & Up \\
\hline KCNJ5 & Potassium inwardly-rectifying channel, subfamily J, member 5 & 0.01 & 1.31 & Up \\
\hline EPOR & Erythropoietin receptor & 0.02 & 1.32 & Up \\
\hline DNAJC21 & DnaJ (Hsp40) homolog, subfamily C, member 21 & 0.049 & 1.33 & Up \\
\hline STAT5B & Signal transducer and activator of transcription $5 \mathrm{~B}$ & 0.012 & 1.33 & Up \\
\hline FST & Follistatin & 0.021 & 1.37 & $\mathrm{Up}$ \\
\hline CD84 & CD84 molecule & 0.033 & 1.37 & Up \\
\hline THRA & Thyroid hormone receptor, alpha & 0.017 & 1.37 & Up \\
\hline MAPK8IP3 & Mitogen-activated protein kinase 8 interacting protein 3 & 0.028 & 1.4 & $\mathrm{Up}$ \\
\hline SIAE & Sialic acid acetylesterase & 0.01 & 2.42 & Up \\
\hline HINT3 & Histidine triad nucleotide-binding protein 3 & 0.033 & 2.6 & Up \\
\hline
\end{tabular}

The table shows the list of overexpressed genes by 1.3 -fold with a $P$ value $<0.05$ obtained in cells treated with caffeic acid and includes the gene symbol for all genes, their associated description. The ratio columns correspond to the absolute fold change in expression relative to the control group and the type of regulation (up: upregulation).

levels in HT29 cells. STAT5 was originally described as a prolactin-induced mammary gland factor [33]. The cloning of two closely related STAT5 cDNAs, from both mouse and human cDNA libraries, showed two distinct genes, STAT5A and STAT5B that encoded two STAT5 proteins [34-37].

In addition to prolactin, STAT5 proteins are activated by a wide variety of cytokines and growth factors, including IL-2, IL-3, IL-5, IL-7, IL-9, IL-15, granulocyte-macrophage colony-stimulating factor, erythropoietin, growth hormone, thrombopoietin, epidermal growth factor, and plateletderived growth factor. The key function of STAT5B is to mediate the effects of growth hormone [38, 39]. Modulation of STAT5 levels or transcriptional activity has already been described in cells treated with natural compounds such as nobiletin, a citrus flavonoid [40], thea flavins [41], and silibinin, a natural polyphenolic flavonoid which is a major bioactive component of silymarin isolated from Silybum marianum [42]. Furthermore, it has been reported that 
TABLE 5: List of underexpressed genes in HT29 cells upon incubation with caffeic acid.

\begin{tabular}{|c|c|c|c|c|}
\hline Gene symbol & Gene title & $P$ value & FC absolute & Regulation \\
\hline MFSD7 & Major facilitator superfamily domain containing 7 & $1.00 \mathrm{E}-04$ & 1.3 & Down \\
\hline MSI2 & Musashi homolog 2 (Drosophila) & 0.027 & 1.3 & Down \\
\hline $\mathrm{CDA}$ & Cytidine deaminase & $2.00 \mathrm{E}-04$ & 1.31 & Down \\
\hline DEFB1 & Defensin, beta 1 & 0.026 & 1.31 & Down \\
\hline PIP5K1A & Phosphatidylinositol-4-phosphate 5-kinase, type I, alpha & 0.027 & 1.31 & Down \\
\hline ZDHHC20 & Zinc finger, DHHC-type containing 20 & 0.005 & 1.31 & Down \\
\hline ZDHHC21 & Zinc finger, DHHC-type containing 21 & 0.016 & 1.31 & Down \\
\hline SLC4A7 & Solute carrier family 4 , member 7 & 0.0249 & 1.32 & Down \\
\hline CEACAM 1 & Carcinoembryonic antigen-related cell adhesion molecule 1 & 0.0459 & 1.32 & Down \\
\hline PDZRN3 & PDZ domain containing RING finger 3 & 0.002 & 1.32 & Down \\
\hline WDR62 & WD repeat domain 62 & 0.005 & 1.32 & Down \\
\hline FAM76B & Family with sequence similarity 76 , member B & 0.036 & 1.32 & Down \\
\hline TCF21 & Transcription factor 21 & 0.029 & 1.33 & Down \\
\hline TBL1XR1 & Transducin (beta)-like $1 \mathrm{X}$-linked receptor 1 & $6.00 \mathrm{E}-04$ & 1.33 & Down \\
\hline CLK4 & CDC-like kinase 4 & 0.021 & 1.33 & Down \\
\hline CYP2A13 & Cytochrome P450, family 2, subfamily A, polypeptide 13 & 0.009 & 1.34 & Down \\
\hline CXCR4 & Chemokine (C-X-C motif) receptor 4 & 0.0488 & 1.34 & Down \\
\hline ATF2 & Activating transcription factor 2 & 0.0158 & 1.35 & Down \\
\hline PDE10A & Phosphodiesterase 10A & 0.03 & 1.35 & Down \\
\hline METT10D & Methyltransferase 10 domain containing & 0.003 & 1.35 & Down \\
\hline PRMT2 & Protein arginine methyltransferase 2 & $7.00 \mathrm{E}-04$ & 1.36 & Down \\
\hline GLS & Glutaminase & $5.70 \mathrm{E}-04$ & 1.37 & Down \\
\hline SLC38A5 & Solute carrier family 38 , member 5 & 0.043 & 1.37 & Down \\
\hline TINAG & Tubulointerstitial nephritis antigen & 0.043 & 1.38 & Down \\
\hline AQP1 & Aquaporin 1 (Colton blood group) & 0.0221 & 1.4 & Down \\
\hline JMJD6 & Jumonji domain containing 6 & 0.004 & 1.4 & Down \\
\hline SAP30L & SAP30-like & 0.021 & 1.4 & Down \\
\hline FGD4 & FYVE, RhoGEF, and PH domain containing 4 & 0.026 & 1.52 & Down \\
\hline S100A2 & S100 calcium-binding protein A2 & 0.005 & 1.53 & Down \\
\hline CTSZ & Cathepsin Z & 0.045 & 1.53 & Down \\
\hline SLC4A4 & Solute carrier family 4 , member 4 & $9.00 \mathrm{E}-04$ & 1.54 & Down \\
\hline AGR3 & Anterior gradient homolog 3 (Xenopus laevis) & 0.011 & 1.69 & Down \\
\hline
\end{tabular}

The table shows the list of underexpressed genes by 1.3 -fold with a $P$ value $<0.05$ obtained in cells treated with caffeic acid and includes the gene symbol for all genes, their associated description. The ratio columns correspond to the absolute fold change in expression relative to the control group and the type of regulation (down: downregulation).

butein, the major biologically active polyphenolic component of the stems of Rhus verniciflua, downregulated the expression of STAT3-regulated gene products such as Bcl-xL, Bcl-2, cyclin D1, and Mcl-1 [43].

STAT5B participates in diverse biological processes, such as growth development, immunoregulation, apoptosis, reproduction, prolactin pathway, and lipid metabolism. STAT5B deficiency is a recently identified disease entity that involves both severe growth hormone-resistant growth failure and severe immunodeficiency [44-46]. The induction of STAT5B expression upon incubation with CA and ICC could represent a nutritional tool to upregulate this transcription factor and suggests novel research strategies for natural therapies in Crohn's disease and inflammatory bowel disease in which STAT5B appears to maintain the mucosal barrier integrity and tolerance $[47,48]$. In colorectal cancer both STAT5a and STAT5b play important roles in progression and downregulation of both STAT5A and STAT5B results in a gradual decrease in cell viability, predominantly attributed to G1 cell cycle arrest, and apoptotic cell death [49]. In this context the increase in STAT5B caused by ICC and CA would have a negative effect on colorectal cancer patients, as it would trigger cell proliferation and survival.

In human breast cancer, STAT5A/B has been shown a dual role in the mammary gland as an initiator of tumor formation as well as a promoter of differentiation of established tumors. STAT3, STAT5A, and STAT5B are overexpressed or constitutively activated in breast cancer [5052] and active STAT5A/B in human breast cancer predicted favorable clinical outcome [53]. Prolactin receptor signal 
TABLE 6: Common differentially expressed genes in HT29 treated-cells.

\begin{tabular}{lcccccc}
\hline Gene symbol & FC absolute ICC & $P$ value & Regulation & FC absolute CA & $P$ value & Regulation \\
\hline FST & 1.343 & 0.025 & Up & 1.375 & 0.022 & Up \\
SULT1B1 & 1.349 & 0.018 & Up & 1.304 & 0.020 & Up \\
EPOR & 1.372 & 0.008 & Up & 1.321 & 0.021 & Up \\
HINT3 & 2.410 & 0.040 & Up & 2.607 & 0.033 & Up \\
STAT5B & $\mathbf{1 . 3 1 2}$ & $\mathbf{0 . 0 0 7}$ & Up & $\mathbf{1 . 3 3 4}$ & $\mathbf{0 . 0 1 2}$ & Up \\
GLS & 1.335 & 0.001 & Down & 1.370 & 0.001 & Down \\
PPP3R1 & 1.397 & 0.023 & Down & 1.423 & 0.026 & Down \\
ATF2 & $\mathbf{1 . 4 8 1}$ & $\mathbf{0 . 0 0 5}$ & Down & $\mathbf{1 . 3 5 4}$ & $\mathbf{0 . 0 1 6}$ & Down \\
SLC4A7 & 1.314 & 0.029 & Down & 1.322 & 0.025 & Down \\
MARCH3 & 1.330 & 0.016 & Down & 1.319 & 0.005 & Down \\
TBL1XR1 & 1.426 & 0.001 & Down & 1.332 & 0.001 & Down \\
SAP30L & 1.375 & 0.013 & Down & 1.405 & 0.021 & Down \\
FGD4 & 1.593 & 0.001 & Down & 1.523 & 0.027 & Down \\
ZDHHC20 & 1.665 & 0.004 & Down & 1.314 & 0.005 & Down \\
ZDHHC21 & 1.642 & 0.037 & Down & 1.318 & 0.016 & Down \\
FAM76B & 1.506 & 0.014 & Down & 1.325 & 0.037 & Down \\
CLK4 & 1.326 & 0.049 & Down & 1.339 & 0.021 & Down \\
\hline
\end{tabular}

Common differentially expressed genes in HT29 treated-cells with a $P$ value $<0.05$ and a minimum fold of 1.3. Column ICC correspond to cells treated with instant caffeinated coffee and column CA corresponds to cells treated with caffeic acid. Overexpressed genes are indicated on the upper part of the table, whereas underexpressed genes are depicted in the lower part. The genes in bold, STAT5B and ATF-2, were chosen for further analysis.

transduction through the Jak2-STAT5 pathway has been considered to be essential for proliferation and differentiation of normal mammary epithelial cells [54-56]. It has been shown that the levels of NUC-pYSTAT5 decreased as breast cancer progressed from normal to in situ, to invasive, and then to nodal metastases [57]. Additionally Peck et al. [57] found that the absence of detectable NUC-pYStat5 in tumors of patients how where under antiestrogen therapy was associated with poor breast cancer-specific survival. We analyzed STAT5B modulation through the PRL pathway in response to coffee polyphenols in a breast cancer cell line. The MCF-7 cell line was chosen because expression of the prolactin receptor is more often found in estrogen receptorpositive breast tumors [58]. In our conditions, incubation with CA and ICC led to an increase in STAT5B protein levels in MCF-7 cells, and this result could be the basis for a possible inclusion of coffee polyphenols in the diet of breast cancer patients.

ATF-2 is a member of the ATF-cAMP response elementbinding protein (CREB) family of transcription factors that can bind to the cAMP response element (CRE) found in many mammalian gene promoters $[59,60]$. ATF-2 exhibits both oncogenic and tumor suppressor functions [61]. CREs are found in several genes involved in the control of the cell cycle, for example, the cyclin D1 gene, and ATF-2 binding to this sequence stimulates the transcription of cyclin D1 $[30,31]$. ATF-2 mediated cyclin D1 promoter induction can be stimulated by a number of growthpromoting agents, such as estrogen [31], hepatocyte growth factor [62], and regenerating gene product [63]. ATF-2 has been correlated with proliferation, invasion, migration, and resistance to DNA-damaging agents in breast cancer cell lines.
The downregulation of ATF-2 expression after CA and ICC incubation in HT29 cells reported here is in accordance with the observed decrease in activity of ATF-2 in gastric cells when incubating with chlorogenic acid, the precursor of caffeic acid [64]. Surprisingly, the validation of the protein levels showed the upregulation of ATF2 protein with ICC, but not with CA, both in HT29 and MCF-7 cells. This differential behavior could be due to other ICC components besides CA. In this direction Rubach et al. [64] reported a different response in ATF-2 activity after incubation of a gastric cell line with different coffee compounds. The presence of pyrogallol, catechol, $\beta \mathrm{N}$-alkanoylhydroxytryptamides, and $\mathrm{N}$-methylpyridinium increased ATF-2 activity, whereas chlorogenic acid and caffeine decrease it [64]. In our conditions incubation of HT29 cells with ICC caused a modest decrease in ATF-2 mRNA levels. However this effect was not translated at the protein level. We hypothesize that ICC contains other polyphenols in addition to caffeic acid that are able to increase ATF2 protein levels through an increase of the translation of its mRNA, the increase of stability of the protein or an inhibition of its degradation. In this direction several plant polyphenols such as (-)-epigallocatechins-3-gallate (EGCG), genistein, luteolin, apigenin, chrysin, quercetin, curcumin, and tannic acid have been described to possess proteasomeinhibitory activity $[65,66]$.

The regulation of ATF-2 transcriptional activity, mostly at the level of its phosphorylation status, has been described upon treatment of cancer cells with several natural compounds. In MCF-7 cells, the anticancer agent 3,30-Diindolylmethane, derived from Brassica vegetables, activates both JNK and p38 pathways, resulting in c-Jun and ATF-2 phosphorylation, and the increase of binding of the 
c-Jun-ATF-2 homodimers and heterodimers to the proximal regulatory element of IFN- $\gamma$ promoter [67]. Biochanin-A, an isoflavone, existing in red clover, cabbage and alfalfa, has an inhibitory and apoptogenic effect on certain cancer cells by blocking the phosphorylation of p38 MAPK and ATF-2 in a dose-dependent fashion [68]. The JNK stress-activated pathway is one of the major intracellular signal transduction cascades involved in intestinal inflammation [69, 70], and upregulation of ATF-2 has been shown in Crohn's disease $[71,72]$. Thus CA could represent potential therapeutical properties in different states of intestinal inflammation due to its combined effects on STAT5B and ATF-2 in HT29 cells.

Finally, the modulation of cyclin D1, a target of STAT5B and ATF-2 transcription factors, upon incubation with coffee polyphenols was established in colon and breast cancer cells. Cyclin D1 overexpression is common in colorectal cancer, but the findings regarding its prognostic value are conflicting. In a recent study, positive expression of cyclin D1 protein was detected in 95 of 169 colonic adenocarcinoma specimens, and increased cyclin D1 levels were associated with poorer prognosis [73]. Furthermore, there was a significant correlation between the positive expression of $\mathrm{p}$ Stat 5 and cyclin D1 in patients with colonic adenocarcinoma. However, in a second study, cyclin D1 overexpression was associated with improved outcome in a total of 386 patients who underwent surgical resection for colon cancer, classified as TNM stage II or III. Belt et al. [74] showed that low p21, high p53, low cyclin D1, and high AURKA were associated with disease recurrence in stage II and III colon cancer patients. In this context the effect of ICC on cyclin D1 levels could represent either a positive or a negative effect in colon cancer cells, depending on tumor progression. The increase in cyclin D1 levels could represent a marker of better outcome since it has been recently established that cyclin D1 expression is strongly associated with prolonged survival in male colorectal cancer and that lack of cyclin D1 is associated with a more aggressive phenotype in male patients [75]. However, several natural compounds such as anthocyanins, anthocyanidins, apigenin, luteolin, and fisetin have all been described to induce experimentally cell-cycle arrest and apoptosis through the decrease of cyclin D1 levels in HT29 cells [76-80]. In accordance to these data, the increase observed in cyclin D1 levels in HT29 cells upon incubation with ICC could probably be the consequence of the presence of different compounds other than polyphenols in ICC.

In MCF-7 breast cancer cells, cyclin D1 was downregulated upon incubation with coffee polyphenols. The rationale for the choice of MCF-7 cell line was based on the observation that although cyclin D1 overexpression is present across multiple histologic subtypes of breast cancer, it has been shown that the large majority of cyclin D1overexpressing breast cancers are ER positive [24, 25, 81]. Cyclin D1 overexpression has been reported between 40 and $90 \%$ of cases of invasive breast cancer, while gene amplification is seen in about 5-20\% of tumors [24, 81-83]. In cyclin D1-driven cancers, blocking cyclin D1 expression by targeting the cyclin D1 gene, RNA, or protein should increase the chances for therapeutic success. Cell culture studies have raised the possibility that certain compounds might act in this way $[84,85]$ and approaches to blocking cyclin D1 expression using antisense, siRNA, or related molecules specifically target the driving molecular lesion itself [86-88]. It is believed that compounds that modulate cyclin D1 expression could have a role in the prevention and treatment of human neoplasias. For instance, flavopiridol, a synthetic flavonoid based on an extract from an Indian plant for the potential treatment of cancer, induces a rapid decline in cyclin D1 steady-state protein levels [89]. Taking all these results together, inhibition of cyclin D1 expression appears to be a good approach for cancer treatment. In this direction our observation that coffee and caffeic acid are able to drastically reduce the expression of cyclin D1 in breast cancer cells could suggest that some coffee components could be used as a coadjuvant therapeutic tool in the treatment of breast cancer.

\section{Abbreviations}

APRT: Adenine phosphoribosyltransferase

ATF-2: Activating transcription factor

BAN: Biological association network

CA: $\quad$ Caffeic acid

DMSO: Dimethyl sulfoxide

DEPC: Diethyl pyrocarbonate

ICC: Instant caffeinated coffee

RT-PCR: Reverse transcription-polymerase chain reaction

STAT5B: Signal transducer and activator of transcription $5 B$.

\section{Acknowledgments}

This work was supported by Grants CDTI 050618, SAF20080043, SAF2011-23582 (Ministerio de Educación y Ciencia de España), and ISCIII-RTICc RD06/0020 (Redes Temáticas de Investigación Cooperativa en Salud) RD06/0020/0046. Our research group holds the "quality distinction" from the "Generalitat de Catalunya” SGR2009-00118. C. Oleaga was a recipient of a fellowship from the FEC (Federación Española del Café). All the authors have no conflict of interests.

\section{References}

[1] A. Scalbert, C. Manach, C. Morand, C. Rémésy, and L. Jiménez, "Dietary polyphenols and the prevention of diseases," Critical Reviews in Food Science and Nutrition, vol. 45, no. 4, pp. 287-306, 2005.

[2] A. Scalbert, I. T. Johnson, and M. Saltmarsh, "Polyphenols: antioxidants and beyond," The American Journal of Clinical Nutrition, vol. 81, no. 1, pp. 215S-217S, 2005.

[3] A. Azzi, K. J. Davies, and F. Kelly, "Free radical biologyterminology and critical thinking," FEBS Letters, vol. 558, no. 1-3, pp. 3-6, 2004.

[4] B. Halliwell, J. Rafter, and A. Jenner, "Health promotion by flavonoids, tocopherols, tocotrienols, and other phenols: direct or indirect effects? Antioxidant or not?" The American Journal of Clinical Nutrition, vol. 81, no. 1, pp. 268S-276S, 2005. 
[5] M. R. Olthof, P. C. Hollman, and M. B. Katan, "Chlorogenic acid and caffeic acid are absorbed in humans," Journal of Nutrition, vol. 131, no. 1, pp. 66-71, 2001.

[6] M. R. Olthof, P. C. Hollman, M. N. Buijsman, J. M. van Amelsvoort, and M. B. Katan, "Chlorogenic acid, quercetin-3rutinoside and black tea phenols are extensively metabolized in humans," Journal of Nutrition, vol. 133, no. 6, pp. 18061814, 2003.

[7] C. A. Rice-Evans, N. J. Miller, and G. Paganga, "Structureantioxidant activity relationships of flavonoids and phenolic acids," Free Radical Biology and Medicine, vol. 20, no. 7, pp. 933-956, 1996.

[8] Y. Kono, H. Shibata, Y. Kodama, and Y. Sawa, "The suppression of the N-nitrosating reaction by chlorogenic acid," The Biochemical Journal, vol. 312, part 3, pp. 947-953, 1995.

[9] H. Shibata, Y. Sakamoto, M. Oka, and Y. Kono, "Natural antioxidant, chlorogenic acid, protects against DNA breakage caused by monochloramine," Bioscience, Biotechnology and Biochemistry, vol. 63, no. 7, pp. 1295-1297, 1999.

[10] H. Kasai, S. Fukada, Z. Yamaizumi, S. Sugie, and H. Mori, "Action of chlorogenic acid in vegetables and fruits as an inhibitor of 8-hydroxydeoxyguanosine formation in vitro and in a rat carcinogenesis model," Food and Chemical Toxicology, vol. 38, no. 5, pp. 467-471, 2000.

[11] R. Feng, Y. Lu, L. L. Bowman, Y. Qian, V. Castranova, and M. Ding, "Inhibition of activator protein-1, NF- $\kappa \mathrm{B}$, and MAPKs and induction of phase 2 detoxifying enzyme activity by chlorogenic acid," The Journal of Biological Chemistry, vol. 280, no. 30, pp. 27888-27895, 2005.

[12] S. C. Larsson and A. Wolk, "Coffee consumption and risk of liver cancer: a meta-analysis," Gastroenterology, vol. 132, no. 5, pp. 1740-1745, 2007.

[13] F. Bravi, C. Bosetti, A. Tavani et al., "Coffee drinking and hepatocellular carcinoma risk: a meta-analysis," Hepatology, vol. 46, no. 2, pp. 430-435, 2007.

[14] Y. Je, W. Liu, and E. Giovannucci, "Coffee consumption and risk of colorectal cancer: a systematic review and meta-analysis of prospective cohort studies," International Journal of Cancer, vol. 124, no. 7, pp. 1662-1668, 2009.

[15] N. Tang, B. Zhou, B. Wang, and R. Yu, "Coffee consumption and risk of breast cancer: a metaanalysis," American Journal of Obstetrics and Gynecology, vol. 200, no. 3, pp. 290.e1-290.e9, 2009.

[16] T. Naganuma, S. Kuriyama, M. Kakizaki et al., "Coffee consumption and the risk of oral, pharyngeal, and esophageal cancers in Japan: the Miyagi Cohort Study," American Journal of Epidemiology, vol. 168, no. 12, pp. 1425-1432, 2008.

[17] K. M. Wilson, J. L. Kasperzyk, J. R. Rider et al., "Coffee consumption and prostate cancer risk and progression in the health professionals follow-up study," Journal of the National Cancer Institute, vol. 103, no. 11, pp. 876-884, 2011.

[18] A. Nkondjock, "Coffee consumption and the risk of cancer: an overview," Cancer Letters, vol. 277, no. 2, pp. 121-125, 2009.

[19] D. Ganmaa, W. C. Willett, T. Y. Li et al., "Coffee, tea, caffeine and risk of breast cancer: a 22-year follow-up," International Journal of Cancer, vol. 122, no. 9, pp. 2071-2076, 2008.

[20] J. Li, P. Seibold, J. Chang-Claude et al., "Coffee consumption modifies risk of estrogen-receptor negative breast cancer," Breast Cancer Research, vol. 13, no. 3, article R49, 2011.

[21] T. Mosmann, "Rapid colorimetric assay for cellular growth and survival: application to proliferation and cytotoxicity assays," Journal of Immunological Methods, vol. 65, no. 1-2, pp. 55-63, 1983.
[22] E. Selga, C. Oleaga, S. Ramírez, M. C. de Almagro, V. Noé, and C. J. Ciudad, "Networking of differentially expressed genes in human cancer cells resistant to methotrexate," Genome Medicine, vol. 1, no. 9, article 83, 2009.

[23] E. Selga, C. Morales, V. Noe, and M. A. Peinado, "Role of caveolin 1, E-cadherin, Enolase 2 and PKCalpha on resistance to methotrexate in human HT29 colon cancer cells," BMC Medical Genomics, vol. 1, article 35, 2008.

[24] C. E. Gillett, A. H. Lee, R. R. Millis, and D. M. Barnes, "Cyclin D1 and associated proteins in mammary ductal carcinoma in situ and atypical ductal hyperplasia," The Journal of Pathology, vol. 184, pp. 396-400, 1998.

[25] M. F. Buckley, K. J. Sweeney, J. A. Hamilton et al., "Expression and amplification of cyclin genes in human breast cancer," Oncogene, vol. 8, no. 8, pp. 2127-2133, 1993.

[26] E. J. Lim, Y. H. Joung, S. M. Jung et al., "Hemin inhibits cyclin D1 and IGF-1 expression via STAT5b under hypoxia in ER $\alpha$-negative MDA-MB 231 breast cancer cells," International Journal of Oncology, vol. 36, no. 5, pp. 1243-1251, 2010.

[27] Y. H. Joung, E. J. Lim, M. S. Kim et al., "Enhancement of hypoxia-induced apoptosis of human breast cancer cells via STAT5b by momilactone B," International Journal of Oncology, vol. 33 , no. 3, pp. 477-484, 2008.

[28] E. M. Fox, T. M. Bernaciak, J. Wen, A. M. Weaver, M. A. Shupnik, and C. M. Silva, "Signal transducer and activator of transcription 5b, c-Src, and epidermal growth factor receptor signaling play integral roles in estrogen-stimulated proliferation of estrogen receptor-positive breast cancer cells," Molecular Endocrinology, vol. 22, no. 8, pp. 1781-1796, 2008.

[29] C. A. Lange, J. K. Richer, T. Shen, and K. B. Horwitz, "Convergence of progesterone and epidermal growth factor signaling in breast cancer: potentiation of mitogen-activated protein kinase pathways," The Journal of Biological Chemistry, vol. 273, no. 47, pp. 31308-31316, 1998.

[30] F. Beier, R. J. Lee, A. C. Taylor, R. G. Pestell, and P. Luvalle, "Identification of the cyclin D1 gene as a target of activating transcription factor 2 in chondrocytes," Proceedings of the National Academy of Sciences of the United States of America, vol. 96, no. 4, pp. 1433-1438, 1999.

[31] M. Sabbah, D. Courilleau, J. Mester, and G. Redeuilh, "Estrogen induction of the cyclin D1 promoter: involvement of a cAMP response-like element," Proceedings of the National Academy of Sciences of the United States of America, vol. 96, no. 20, pp. 11217-11222, 1999.

[32] J. S. Lewis, T. J. Thomas, R. G. Pestell, C. Albanese, M. A. Gallo, and T. Thomas, "Differential effects of $16 \alpha$-hydroxyestrone and 2-methoxyestradiol on cyclin D1 involving the transcription factor ATF-2 in MCF-7 breast cancer cells," Journal of Molecular Endocrinology, vol. 34, no. 1, pp. 91-105, 2005.

[33] H. Wakao, F. Gouilleux, and B. Groner, "Mammary gland factor (MGF) is a novel member of the cytokine regulated transcription factor gene family and confers the prolactin response," EMBO Journal, vol. 13, no. 9, pp. 2182-2191, 1994.

[34] J. Hou, U. Schindler, W. J. Henzel, S. C. Wong, and S. L. McKnight, "Identification and purification of human stat proteins activated in response to interleukin-2," Immunity, vol. 2, no. 4, pp. 321-329, 1995.

[35] X. Liu, G. W. Robinson, F. Gouilleux, B. Groner, and L. Hennighausen, "Cloning and expression of Stat5 and an additional homologue (Stat5b) involved in prolactin signal transduction in mouse mammary tissue," Proceedings of the National Academy of Sciences of the United States of America, vol. 92, no. 19, pp. 8831-8835, 1995. 
[36] J. X. Lin, J. Mietz, W. S. Modi, S. John, and W. J. Leonard, "Cloning of human Stat5B: reconstitution of interleukin-2induced Stat5A and Stat5B DNA binding activity in COS-7 cells," The Journal of Biological Chemistry, vol. 271, no. 18, pp. 10738-10744, 1996.

[37] A. L. Mui, H. Wakao, A. M. O'Farrell, N. Harade, and A. Miyajima, "Interleukin-3, granulocyte-macrophage colony stimulating factor and interleukin-5 transduce signals through two STAT5 homologs," EMBO Journal, vol. 14, no. 6, pp. 11661175, 1995.

[38] G. B. Udy, R. P. Towers, R. G. Snell et al., "Requirement of STAT5b for sexual dimorphism of body growth rates and liver gene expression," Proceedings of the National Academy of Sciences of the United States of America, vol. 94, no. 14, pp. 7239-7244, 1997.

[39] S. Teglund, C. McKay, E. Schuetz et al., "Stat5a and Stat5b proteins have essential and nonessential, or redundant, roles in cytokine responses," Cell, vol. 93, no. 5, pp. 841-850, 1998.

[40] K. Kanda, K. Nishi, A. Kadota, S. Nishimoto, M. C. Liu, and T. Sugahara, "Nobiletin suppresses adipocyte differentiation of 3T3-L1 cells by an insulin and IBMX mixture induction," Biochimica et Biophysica Acta, vol. 1820, no. 4, pp. 461-468, 2011.

[41] S. Chattopadhyay, S. Bhattacharyya, B. Saha et al., "Tumorshed PGE2 impairs IL2R $\gamma$ c-signaling to inhibit CD4+ T cell survival: regulation by theaflavins," PLoS ONE, vol. 4, no. 10, Article ID e7382, 2009.

[42] R. P. Singh, K. Raina, G. Deep, D. Chan, and R. Agarwal, "Silibinin suppresses growth of human prostate carcinoma PC3 orthotopic xenograft via activation of extracellular signalregulated kinase $1 / 2$ and inhibition of signal transducers and activators of transcription signaling," Clinical Cancer Research, vol. 15, no. 2, pp. 613-621, 2009.

[43] M. K. Pandey, B. Sung, K. S. Ahn, and B. B. Aggarwal, "Butein suppresses constitutive and inducible signal transducer and activator of transcription (stat) 3 activation and stat3regulated gene products through the induction of a protein tyrosine phosphatase SHP-1," Molecular Pharmacology, vol. 75, no. 3, pp. 525-533, 2009.

[44] K. Nadeau, V. Hwa, and R. G. Rosenfeld, "STAT5b deficiency: an unsuspected cause of growth failure, immunodeficiency, and severe pulmonary disease," Journal of Pediatrics, vol. 158, no. 5, pp. 701-708, 2011.

[45] P. A. Scaglia, A. S. Martinez, E. Feigerlova et al., "A novel missense mutation in the $\mathrm{SH} 2$ domain of the STAT5B gene results in a transcriptionally inactive STAT5b associated with severe IGF-I deficiency, immune dysfunction, and lack of pulmonary disease," The Journal of Clinical Endocrinology \& Metabolism, vol. 97, pp. E830-E839, 2012.

[46] P. Rotwein, "Mapping the growth hormone-Stat5b-IGF-I transcriptional circuit," Trends in Endocrinology \& Metabolism, vol. 23, pp. 186-193, 2012.

[47] X. Han, B. Osuntokun, N. Benight, K. Loesch, S. J. Frank, and L. A. Denson, "Signal transducer and activator of transcription $5 \mathrm{~b}$ promotes mucosal tolerance in pediatric Crohn's disease and murine colitis," American Journal of Pathology, vol. 169, no. 6, pp. 1999-2013, 2006.

[48] X. Han, X. Ren, I. Jurickova et al., "Regulation of intestinal barrier function by signal transducer and activator of transcription 5b," Gut, vol. 58, no. 1, pp. 49-58, 2009.

[49] W. Du, Y. C. Wang, J. Hong et al., "STAT5 isoforms regulate colorectal cancer cell apoptosis via reduction of mitochondrial membrane potential and generation of reactive oxygen species," Journal of Cellular Physiology, vol. 227, pp. 24212429, 2012.

[50] R. Garcia, T. L. Bowman, G. Niu et al., "Constitutive activation of Stat3 by the Src and JAK tyrosine kinases participates in growth regulation of human breast carcinoma cells," Oncogene, vol. 20, no. 20, pp. 2499-2513, 2001.

[51] R. Garcia, C. L. Yu, A. Hudnall et al., "Constitutive activation of Stat 3 in fibroblasts transformed by diverse oncoproteins and in breast carcinoma cells," Cell Growth and Differentiation, vol. 8, no. 12, pp. 1267-1276, 1997.

[52] H. Yamashita, H. Iwase, T. Toyama, and Y. Fujii, "Naturally occurring dominant-negative Stat5 suppresses transcriptional activity of estrogen receptors and induces apoptosis in T47D breast cancer cells," Oncogene, vol. 22, no. 11, pp. 1638-1652, 2003.

[53] S. H. Tan and M. T. Nevalainen, "Signal transducer and activator of transcription 5A/B in prostate and breast cancers," Endocrine-Related Cancer, vol. 15, no. 2, pp. 367-390, 2008.

[54] H. Yamashita and H. Iwase, "The role of Stat5 in estrogen receptor-positive breast cancer," Breast Cancer, vol. 9, no. 4, pp. 312-318, 2002.

[55] J. Frasor, U. Barkai, L. Zhong, A. T. Fazleabas, and G. Gibori, "PRL-induced ER $\alpha$ gene expression is mediated by Janus kinase 2 (Jak2) while signal transducer and activator of transcription $5 \mathrm{~b}$ (Stat5b) phosphorylation involves Jak2 and a second tyrosine kinase," Molecular Endocrinology, vol. 15, no. 11, pp. 1941-1952, 2001.

[56] J. Frasor and G. Gibori, "Prolactin regulation of estrogen receptor expression," Trends in Endocrinology \& Metabolism, vol. 14, no. 3, pp. 118-123, 2003.

[57] A. R. Peck, A. K. Witkiewicz, C. Liu et al., "Loss of nuclear localized and tyrosine phosphorylated Stat5 in breast cancer predicts poor clinical outcome and increased risk of antiestrogen therapy failure," Journal of Clinical Oncology, vol. 29, no. 18, pp. 2448-2458, 2011.

[58] C. Perotti, R. Liu, C. T. Parusel et al., "Heat shock protein90-alpha, a prolactin-STAT5 target gene identified in breast cancer cells, is involved in apoptosis regulation," Breast Cancer Research, vol. 10, no. 6, article R94, 2008.

[59] T. W. Hai, F. Liu, W. J. Coukos, and M. R. Green, "Transcription factor ATF cDNA clones: an extensive family of leucine zipper proteins able to selectively form DNA-binding heterodimers," Genes and Development, vol. 3, no. 12, pp. 2083-2090, 1989.

[60] D. M. Benbrook and N. C. Jones, "Heterodimer formation between CREB and JUN proteins," Oncogene, vol. 5, no. 3, pp. 295-302, 1990.

[61] A. Bhoumik and Z. Ronai, "ATF2: a transcription factor that elicits oncogenic or tumor suppressor activities," Cell Cycle, vol. 7, no. 15, pp. 2341-2345, 2008.

[62] J. A. Recio and G. Merlino, "Hepatocyte growth factor/scatter factor activates proliferation in melanoma cells through p38 MAPK, ATF-2 and cyclin D1," Oncogene, vol. 21, no. 7, pp. 1000-1008, 2002.

[63] S. Takasawa, T. Ikeda, T. Akiyama et al., "Cyclin D1 activation through ATF-2 in Reg-induced pancreatic $\beta$-cell regeneration," FEBS Letters, vol. 580, no. 2, pp. 585-591, 2006.

[64] M. Rubach, R. Lang, E. Seebach, M. M. Somoza, T. Hofmann, and V. Somoza, "Multi-parametric approach to identify coffee components that regulate mechanisms of gastric acid secretion," Molecular Nutrition \& Food Research, vol. 56, pp. 325-335, 2012. 
[65] T. Mujtaba and Q. P. Dou, "Black tea polyphenols inhibit tumor proteasome activity," In Vivo, vol. 26, pp. 197-202, 2012.

[66] M. Shen, T. H. Chan, and Q. P. Dou, "Targeting tumor ubiquitin-proteasome pathway with polyphenols for chemosensitization," Anti-Cancer Agents in Medicinal Chemistry. In press.

[67] L. Xue, G. L. Firestone, and L. F. Bjeldanes, "DIM stimulates IFN $\gamma$ gene expression in human breast cancer cells via the specific activation of JNK and p38 pathways," Oncogene, vol. 24, no. 14, pp. 2343-2353, 2005.

[68] L. Kole, B. Giri, S. K. Manna, B. Pal, and S. Ghosh, "Biochanin-A, an isoflavon, showed anti-proliferative and anti-inflammatory activities through the inhibition of iNOS expression, p38-MAPK and ATF-2 phosphorylation and blocking NFאB nuclear translocation," European Journal of Pharmacology, vol. 653, no. 1-3, pp. 8-15, 2011.

[69] Y. T. Ip and R. J. Davis, "Signal transduction by the c-Jun Nterminal kinase (JNK)—from inflammation to development," Current Opinion in Cell Biology, vol. 10, no. 2, pp. 205-219, 1998.

[70] B. Romier, Y. J. Schneider, Y. Larondelle, and A. During, "Dietary polyphenols can modulate the intestinal inflammatory response," Nutrition Reviews, vol. 67, no. 7, pp. 363-378, 2009.

[71] E. Hollenbach, M. Vieth, A. Roessner, M. Neumann, P. Malfertheiner, and M. Naumann, "Inhibition of RICK/nuclear factor- $\kappa \mathrm{B}$ and $\mathrm{p} 38$ signaling attenuates the inflammatory response in a murine model of Crohn disease," The Journal of Biological Chemistry, vol. 280, no. 15, pp. 14981-14988, 2005.

[72] S. Derer, G. H. Waetzig, D. Seegert, S. Nikolaus, S. Schreiber, and P. Rosenstiel, "A possible link between TIMP-1 induction and response to infliximab," Gut, vol. 58, no. 6, pp. 888-889, 2009.

[73] Y. Mao, Z. Li, C. Lou, and Y. Zhang, "Expression of phosphorylated Stat5 predicts expression of cyclin D1 and correlates with poor prognosis of colonic adenocarcinoma," International Journal of Colorectal Disease, vol. 26, no. 1, pp. 29-35, 2011.

[74] E. J. Belt, R. P. Brosens, P. M. Delis-van Diemen et al., "Cell cycle proteins predict recurrence in stage II and III colon cancer," Annals of Surgical Oncology. In press.

[75] S. Wangefjord, J. Manjer, A. Gaber, B. Nodin, J. Eberhard, and K. Jirstrom, "Cyclin D1 expression in colorectal cancer is a favorable prognostic factor in men but not in women in a prospective, population-based cohort study," Biology of Sex Differences, vol. 2, article 10, 2011.

[76] C. P. Hsu, Y. T. Shih, B. R. Lin, C. F. Chiu, and C. C. Lin, "Inhibitory effect and mechanisms of an anthocyaninsand anthocyanidins-rich extract from purple-shoot tea on colorectal carcinoma cell proliferation," Journal of Agricultural and Food Chemistry, vol. 60, pp. 3686-3692, 2012.

[77] M. Turktekin, E. Konac, H. I. Onen, E. Alp, A. Yilmaz, and S. Menevse, "Evaluation of the effects of the flavonoid apigenin on apoptotic pathway gene expression on the colon cancer cell line (HT29)," Journal of Medicinal Food, vol. 14, pp. 11071117, 2011.

[78] D. Y. Lim, Y. Jeong, A. L. Tyner, and J. H. Park, "Induction of cell cycle arrest and apoptosis in HT-29 human colon cancer cells by the dietary compound luteolin," American Journal of Physiology, vol. 292, no. 1, pp. G66-G75, 2007.
[79] G. Seelinger, I. Merfort, U. Wölfle, and C. M. Schempp, "Anticarcinogenic effects of the flavonoid luteolin," Molecules, vol. 13, no. 10, pp. 2628-2651, 2008.

[80] Y. Suh, F. Afaq, J. J. Johnson, and H. Mukhtar, "A plant flavonoid fisetin induces apoptosis in colon cancer cells by inhibition of COX2 and Wnt/EGFR/NF- $\kappa \mathrm{B}$-signaling pathways," Carcinogenesis, vol. 30, no. 2, pp. 300-307, 2009.

[81] L. R. Zukerberg, W. I. Yang, M. Gadd et al., "Cyclin D1 (PRAD1) protein expression in breast cancer: approximately one-third of infiltrating mammary carcinomas show overexpression of the cyclin D1 oncogene," Modern Pathology, vol. 8, no. 5, pp. 560-567, 1995.

[82] D. Weinstat-Saslow, M. J. Merino, R. E. Manrow et al., "Overexpression of cyclin D mRNA distinguishes invasive and in situ breast carcinomas from non-malignant lesions," Nature Medicine, vol. 1, no. 12, pp. 1257-1260, 1995.

[83] J. F. Simpson, D. E. Quan, F. O’Malley, T. Odom-Maryon, and P. E. Clarke, "Amplification of CCND1 and expression of its protein product, cyclin D1, in ductal carcinoma in situ of the breast," American Journal of Pathology, vol. 151, no. 1, pp. 161$168,1997$.

[84] C. H. Hsiang and D. S. Straus, "Cyclopentenone causes cell cycle arrest and represses cyclin D1 promoter activity in MCF7 breast cancer cells," Oncogene, vol. 21, no. 14, pp. 2212-2226, 2002.

[85] S. Sawatsri, D. Samid, S. Malkapuram, and N. Sidell, "Inhibition of estrogen-dependent breast cell responses with phenylacetate," International Journal of Cancer, vol. 93, no. 5, pp. 687-692, 2001.

[86] E. R. Sauter, M. Nesbit, S. Litwin, A. J. Klein-Szanto, S. Cheffetz, and M. Herlyn, "Antisense cyclin D1 induces apoptosis and tumor shrinkage in human squamous carcinomas," Cancer Research, vol. 59, no. 19, pp. 4876-4881, 1999.

[87] N. Arber, Y. Doki, E. K. Han et al., "Antisense to cyclin D1 inhibits the growth and tumorigenicity of human colon cancer cells," Cancer Research, vol. 57, no. 8, pp. 1569-1574, 1997.

[88] M. Kornmann, N. Arber, and M. Korc, "Inhibition of basal and mitogen-stimulated pancreatic cancer cell growth by cyclin D1 antisense is associated with loss of tumorigenicity and potentiation of cytotoxicity to cisplatinum," The Journal of Clinical Investigation, vol. 101, no. 2, pp. 344-352, 1998.

[89] B. Carlson, T. Lahusen, S. Singh et al., "Down-regulation of cyclin D1 by transcriptional repression in MCF-7 human breast carcinoma cells induced by flavopiridol," Cancer Research, vol. 59, no. 18, pp. 4634-4641, 1999. 


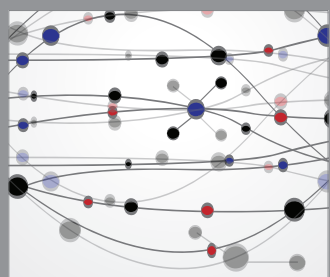

The Scientific World Journal
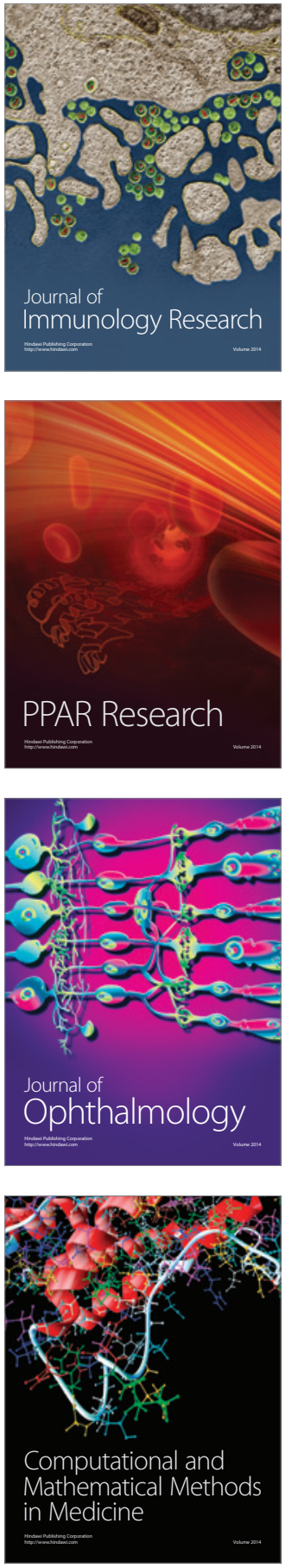

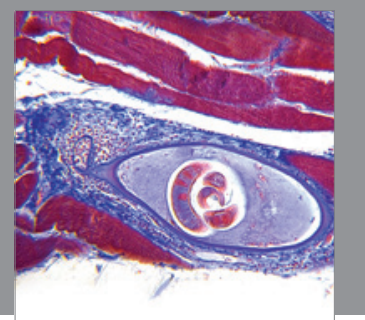

Gastroenterology

Research and Practice
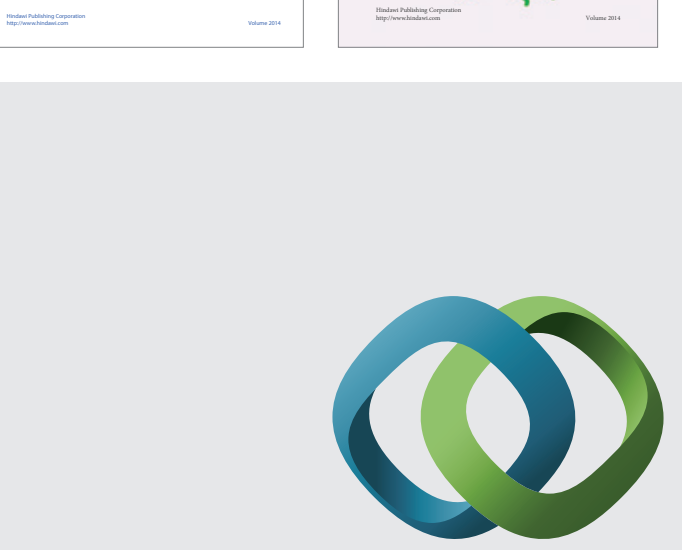

\section{Hindawi}

Submit your manuscripts at

http://www.hindawi.com
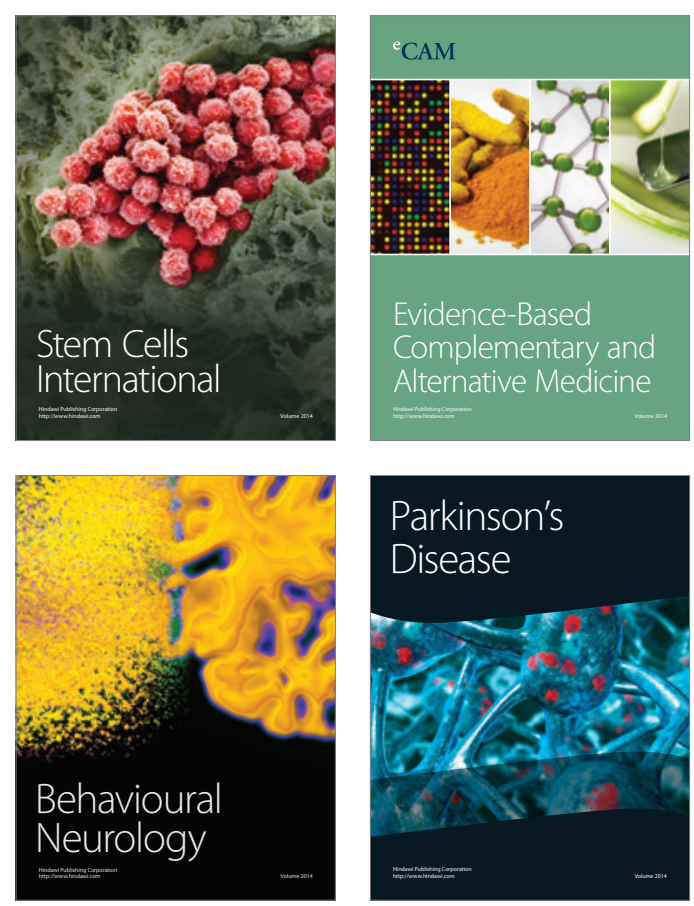

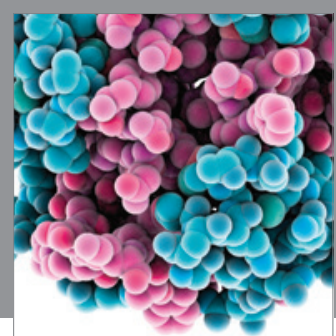

Journal of
Diabetes Research

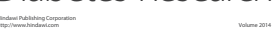

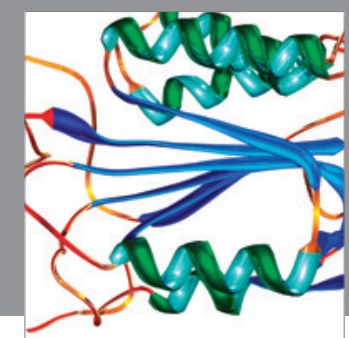

Disease Markers
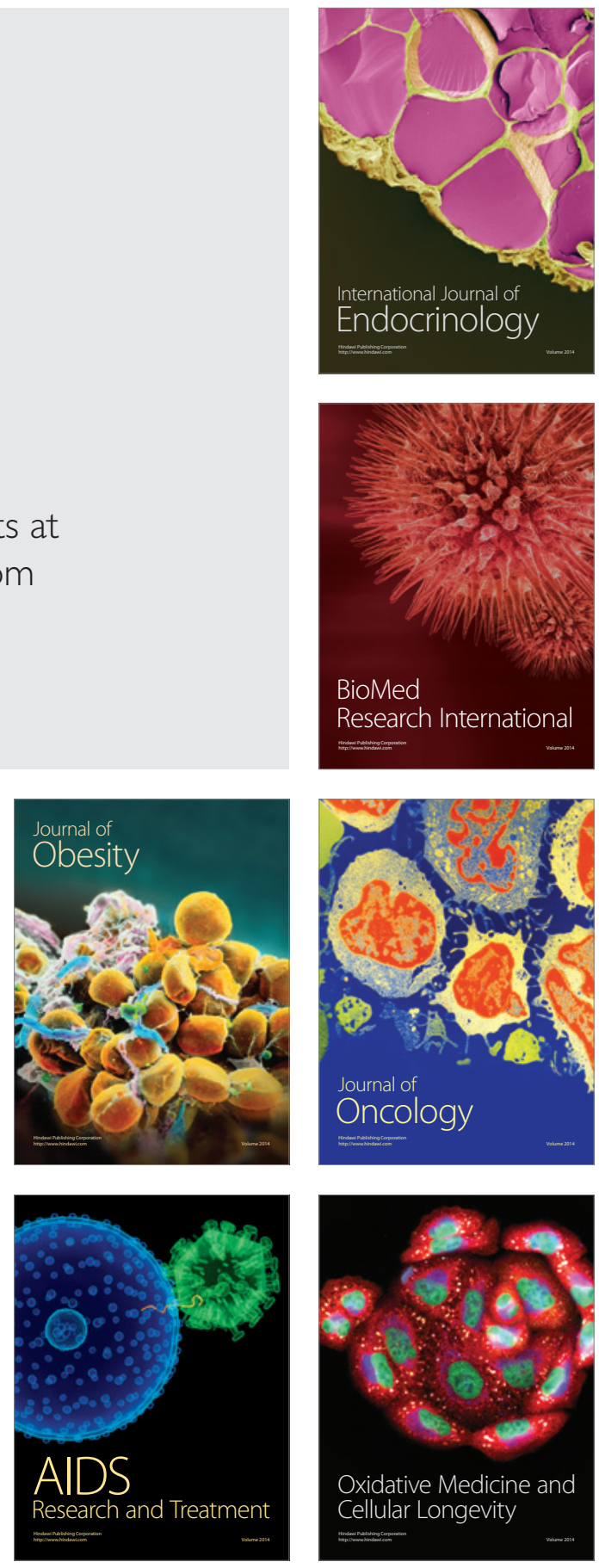